Hispania Sacra, LXII

125, enero-junio 2010, 267-309, ISSN: 0018-215-X

\title{
LEOCADIO LOBO, UN SACERDOTE REPUBLICANO (1887-1959)
}

\author{
POR \\ JosÉ LuIS GONZÁLEZ GULLÓN \\ Universidad de Navarra
}

\section{RESUMEN}

El padre Lobo fue el único sacerdote que residió en Madrid durante la Guerra Civil apoyando públicamente al Gobierno de la República. En el cincuentenario de su muerte, un riguroso estudio documental saca a la luz una vida insospechada donde, entre luces y sombras, aparece la biografía de un hombre que tuvo una profunda identidad sacerdotal, vivió un proceso de rehabilitación en la Iglesia, y colaboró para que fuese la República la que encauzara el progreso político, social y religioso del pueblo español.

PALABRAS CLAVE: Leocadio Lobo, Segunda República española, Guerra Civil, exilio republicano, Isidro Gomá, Leopoldo Eijo Garay, Nueva York, National Catholic Welfare Conference.

\section{LEOCADIO LOBO, A REPUBLICAN PRIEST (1887-1959)}

\section{ABSTRACT}

Father Lobo was the only priest living in Madrid during the Spanish Civil War who supported the Republican Government. In the fiftieth anniversary of his death, this study brings to light the biography of a man who had a deep priestly identity, suffered a rehabilitation process in the Church, and worked for a Republic which should be the final step of the political, social and religious changes that needed to be done in Spain.

KEY WORDS: Leocadio Lobo, Spanish Second Republic, Spanish Civil War, Republican Exile, Cardinal Isidro Gomá, Leopoldo Eijo Garay, New York City, National Catholic Welfare Conference.

Recibido/Received 06-10-2009

Aceptado/Accepted 25-11-2009 
La vida de Leocadio Lobo no ha pasado al olvido en la historia de la Iglesia española de la primera mitad del siglo XX: fue un sacerdote católico que estuvo suspendido y fue rehabilitado, abrazó el republicanismo, condujo una intensa vida pastoral, residió en varios países y fue un personaje de renombre durante la Guerra Civil, tanto en España como en el extranjero.

Tal vez porque hasta ahora no se había accedido a la abundante aunque dispersa documentación sobre su figura, Lobo era un icono de la Guerra Civil, idolatrado por unos y vilipendiado por otros. Las expresiones «gran sacerdote republicano», «renegado padre Lobo» o «propagandista rojo» no son exclusivas de los años treinta. La mayor parte de la historiografía posterior lo ha encasillado unilateralmente, ya sea porque colaboró con los Gobiernos republicanos durante la Guerra Civil, ya porque criticó la actuación política de la Jerarquía española y del Gobierno de Franco. Lobo ha sido un prototipo del conflicto que dividió radicalmente a España y, por eso mismo, su nombre se ha utilizado como un símbolo político.

Las relaciones eclesiales, políticas y culturales de Leocadio Lobo hacen complejo su estudio. La relevancia social de su vida suscita interrogantes que, superando a la persona, se dirigen a la colectividad: son preguntas que giran en torno a la identidad y la vida de los sacerdotes durante la Segunda República y la Guerra Civil, a las actitudes políticas y culturales de los católicos republicanos durante el conflicto fratricida, y al modo de vida que llevaron los católicos exiliados. Temas, en definitiva, de extraordinaria amplitud y riqueza que aparecerán aquí en la medida en que Leocadio Lobo los afrontó.

El artículo está dividido en tres partes que recorren los grandes momentos de la vida del padre Lobo: su actividad parroquial en Madrid, su actividad política durante la Guerra Civil y su exilio en los Estados Unidos. En todo momento, se ha intentado ser lo más expositivo posible, dejando las valoraciones sobre Lobo para las conclusiones. El estudio ha sido posible gracias al trabajo heurístico realizado en once archivos de España, Inglaterra, Ciudad del Vaticano y Estados Unidos. No pretende ser definitivo a la espera de resolver cuestiones todavía oscuras como, por ejemplo, por qué Leocadio decidió hacerse sacerdote o cuáles fueron las razones últimas que le condujeron a abrazar las ideas republicanas. No obstante, este análisis de la figura de Lobo arroja nueva luz sobre la verdad histórica del pasado reciente del pueblo español. ${ }^{1}$

${ }^{1}$ El carácter documental del artículo es la causa de su larga extensión y del poco uso de la bibliografía. Agradezco la benevolencia de Hispania Sacra para publicarlo íntegro.

Hispania Sacra, LXII

125, enero-junio 2010, 267-309, ISSN: 0018-215-X 


\section{El SEMINARIo de SAN DÁmaso (1887-1918)}

Leocadio José Lobo Canónigo vio la luz el 9 de diciembre de 1887 en Batres, un pueblito de un centenar de habitantes, situado a treinta y siete kilómetros al suroeste de Madrid, cuna de la familia de Garcilaso de la Vega. Su padre, Bernardo, era un joven guardabosques de veintitrés años, vecino de Batres. Su madre, Dolores, había nacido en Carranque, distante a sólo diez kilómetros de Batres. Leocadio fue bautizado a los cinco días de nacer, pero no fue legitimado hasta tres años más tarde, cuando sus padres contrajeron matrimonio canónico en mayo de 1890. A pesar de disponer de escasas posibilidades sociales y económicas, el matrimonio tuvo una larguísima descendencia: Leocadio fue el mayor de diecisiete hermanos, de los cuales cuatro murieron poco después de su nacimiento. ${ }^{2}$

En octubre de 1901, Leocadio comenzó sus estudios en el Seminario Conciliar de Madrid «por pura vocación -ya que, en un principio, estuvo destinado al comercio». ${ }^{3}$ Allí iba a permanecer dos lustros, de los catorce a los veinticuatro años, formándose para ser sacerdote. Lobo realizó el plan de estudios previsto -Latín y Humanidades, Filosofía y Teología- recibiendo excelentes calificaciones. Tenía cierta pasión por la expresión oral, como demostró en las veladas literarias organizadas por el Seminario. ${ }^{4}$ Años más tarde, será frecuente que el «elocuente orador» ${ }^{5}$ sea invitado a predicar sermones en iglesias, a dar conferencias y a hablar a través de la radio.

Además de la formación intelectual, Leocadio Lobo fomentó en el Seminario su relación con Dios, con una fe sincera y profunda. En aquellos años de juventud siguió las normas marcadas en los seminarios: misa diaria y oraciones comunitarias, pertenencia a asociaciones piadosas y práctica de devociones particulares. La formación cultural -sobre todo en el modo de entender la sociedad y el papel que en ella juega la Iglesia-, estuvo también marcada por las pautas propugnadas por la Jerarquía: unas líneas de pensamiento tradicionales que, en su afán de desmarcarse del liberalismo, defendían la confesionalidad del Estado. ${ }^{6}$

\footnotetext{
${ }^{2}$ Cfr. Certificado de Bautismo, Batres, 12-V-1912, en Archivo Histórico de la Diócesis de Madrid (en adelante AHDM), Expedientes de Órdenes Sagradas 1913, Leocadio Lobo Canónigo. Siguiendo una práctica habitual en esos años, Leocadio recibió el sacramento de la Confirmación cuando tenía dos años y medio, en junio de 1890 (cfr. Certificado de Confirmación, Batres, 12-V-1912, en AHDM, Expedientes de Órdenes Sagradas 1913, Leocadio Lobo Canónigo).

${ }^{3}$ ABC, 22-XII-1938. Firma el artículo Ángel Ossorio y Gallardo, católico republicano, embajador de España en Francia, Bélgica y Argentina durante la Guerra Civil. Fue gran amigo de Lobo.

${ }^{4}$ Cfr. Boletín Oficial del Obispado de Madrid-Alcalá (en adelante BOOMA), n. 895, 10-III-1910, p. 194.

${ }^{5} A B C, 12-\mathrm{VI}-1921 ; A B C, 12-\mathrm{VI}-1926 ; A B C, 29-\mathrm{VI}-1927$.

${ }^{6}$ Cfr. Primitivo Tineo, «La formación teológica en los seminarios españoles (1890-1925)», Апиаrio de Historia de la Iglesia 2 (1993) p. 93.
} 
El año 1911 fue de gran movilidad para Leocadio. Dejando temporalmente el grupo de amigos del Seminario y la paz de los estudios, Lobo se incorporó al Ejército. Después de la instrucción, pasó a formar parte del Batallón de Cazadores «Las Navasilo» y marchó a la guerra de Marruecos, donde fue herido. ${ }^{7}$ Nunca olvidaría la terrible experiencia de la lucha «contra los moros». Años más tarde, ofrecerá una misa anual en sufragio por los que murieron en la batalla del Barranco del Lobo, lugar en el que había dejado la vida un hermano suyo. ${ }^{8}$

De regreso a España, Leocadio manifestó a José María Salvador Barrera, Obispo de Madrid-Alcalá, su deseo de ser ordenado presbítero. Una vez aceptada la petición, para la cual tuvo que conseguir una dispensa por haber empuñado armas, el proceso fue rápido. En mayo de 1912 recibió la tonsura y las órdenes menores; en enero de 1913, mientras cursaba su último año de estudios de Teología, recibió el subdiaconado; el 16 de mayo fue ordenado diácono; y, finalmente, el 20 de diciembre de 1913 Leocadio Lobo recibió el presbiterado junto a otros diez compañeros. El neosacerdote quedó en la diócesis de Madrid a título de Servitio Ecclesiae, es decir, incardinado y bajo la jurisdicción del Obispo de Madrid-Alcalá. ${ }^{9}$

El obispado de Madrid tenía como práctica habitual enviar a los jóvenes sacerdotes a parroquias de la provincia de Madrid, con el fin de que se enfrentaran con la vida real de un cura de pueblo. Lobo, en cambio, no cambió de residencia. Se quedó en el Seminario Conciliar como prefecto de disciplina y profesor de «Apologética, Catequesis e Historia Sagrada». ${ }^{10}$ Impartía esta asignatura a los «latinos», es decir, a los alumnos de los primeros cursos. Durante cuatro años -de 1914 a 1918- explicó la materia, a la vez que fue recibiendo la formación permanente prevista para los sacerdotes por la ley eclesiástica: las collationes o conferencias sacerdotales, los exámenes de repaso previstos después de la ordenación y la asistencia a los Ejercicios espirituales al menos una vez al trienio.

Desde 1917 Lobo ejercitó una nueva faceta: la acción sindical católica. Durante un lustro fue miembro del Sindicato Agrícola del Sagrado Corazón de su pueblo natal, Batres. La colaboración en el sindicalismo católico demuestra su interés por la acción social, desmarcándose de sus aspectos más doctrinales

${ }^{7}$ Cfr. Heraldo de Cuenca, 28-IX-1936.

${ }^{8}$ El desastre del Barranco del Lobo acaeció en julio de 1909. Allí murieron 153 militares españoles y fueron heridos otros 600. Leocadio ofreció una misa anual entre 1930 y 1934, asistiendo a la misma excombatientes y familiares (La Vanguardia, 29-VII-1930; ABC, 28-VII-1931; ABC, 26-VII-1932; $A B C$, 30-VII-1933; $A B C, 29-\mathrm{VII}-1934)$.

${ }^{9}$ Cfr. BOOMA, n. 1035, 10-I-1914, p. 28.

${ }^{10}$ Cfr. Anuario Eclesiástico, Barcelona, Subirana 1917, p. 179; y Anuario Eclesiástico, Barcelona, Subirana 1918, pp. 151-152. 
y reflexivos -no eran infrecuentes en estos años los «sacerdotes sociólogos»para dar paso a actividades concretas. Lobo dejó este sindicato en 1923, después de haber sido acusado de malversación e incautación de fondos, algo que no pudo probarse. ${ }^{11}$

Las actividades sindicales de Leocadio Lobo llegaron a oídos de Antonio Guerrero García, presidente de la Federación Agrícola Matritense. En 1919, Guerrero solicitó al Obispo de Madrid-Alcalá la dedicación parcial de Leocadio Lobo a la propaganda sindical católico-agraria. El proyecto no salió adelante porque para entonces Lobo estaba trabajando en la parroquia de San José. El sacerdote encargado de esa parroquia respondió negativamente a una consulta previa del Obispo sobre la oportunidad del encargo sindical dadas las «excepcionales condiciones de dicho señor, tanto para el desempeño de los deberes parroquiales como para las obras de acción social».12

\section{LAS PARROQUIAS DE MADRID (1918-1936)}

Con treinta y un años, Leocadio Lobo dejó el Seminario de San Dámaso. Atrás quedaban etapas importantes de su vida que, en definitiva, le habían marcado una clara impronta sacerdotal -lo que es y lo que debe hacer un sacerdoteque mantendrá siempre. Por delante, en cambio, aparecía un desafío que había esperado y preparado: ser un pastor en el rebaño de Jesucristo.

El 7 de septiembre de 1918, Lobo recibió su primer destino en la parroquia de San José, situada al comienzo de la Gran Vía, muy cerca de la Plaza de Cibeles. Allí trabajó como coadjutor de sacramentos, es decir, como sacerdote encargado de administrar los sacramentos cuando estuviese estipulado o cuando éstos hiciesen falta, en especial el de la Extremaunción. Este trabajo originó un conflicto con sus compañeros de parroquia. Fue acerca de las guardias de noche, que en principio Leocadio no debía realizar porque estaba previsto que las llevaran a cabo los coadjutores auxiliares, sacerdotes contratados para esa labor. El párroco consultó el caso al Obispo de Madrid-Alcalá que resolvió a favor de Lobo. ${ }^{13}$

En 1923, Leocadio Lobo pasó a servir como coadjutor primero en la parroquia de San Pedro el Real. Ascendía así de puesto -por encima tenía sólo al pá-

\footnotetext{
${ }^{11}$ Oficio para el Vicario General de la diócesis de Madrid-Alcalá, Madrid, (sin fecha), en AHDM, Personal Antiguo, Legajo 23, Expediente personal de Leocadio Lobo Canónigo.

12 Instancia de Antonio Guerrero y García, Presidente de la Federación Agrícola Matritense al Obispo de Madrid-Alcalá, Madrid, 18-XI-1919, en AHDM, Personal Antiguo, Legajo 23, Expediente personal de Leocadio Lobo Canónigo.

${ }^{13}$ Cfr. Oficio para el Obispo de Madrid-Alcalá, Madrid, 17-II-1921, en AHDM, Personal Antiguo, Legajo 23, Expediente personal de Leocadio Lobo Canónigo.
} 
rroco- y también mejoraba sus ingresos. Éstos provenían de los estipendios recibidos cuando celebraba sacramentos -misa diaria, funerales y bautizos- más un veinte por ciento recibido del presupuesto estatal de culto y clero. ${ }^{14}$

Lobo estuvo en San Pedro seis años. Durante esa época concluyó su formación académica: en 1926 se licenció en Derecho Canónico y al año siguiente consiguió el doctorado por la Pontificia Universidad de Toledo. ${ }^{15}$ Aunque muchas tesis del momento no pasaban de ser trabajos de fácil abordaje, resulta significativo que Leocadio hubiese continuado con el estudio, pues estaba trabajando en una importante parroquia y tenía ya cuarenta años.

El 11 de julio de 1926, Leocadio fue invitado a predicar el sermón de la primera misa de su amigo Tomás Viorreta del Olmo. «Al recordar el Sr. Lobo el origen humilde del celebrante y de su padre, obrero que vive de su honrado trabajo, ensalzó, en elocuentes párrafos, el amor que Jesucristo tuvo a la clase trabajadora, amparándola con sus doctrinas». ${ }^{16}$ Después anunció al nuevo cura que su trabajo iba a ser apasionante y duro al mismo tiempo: «Excitó al nuevo sacerdote a sacrificarse en el cumplimiento de su deber, donde encontrará más amarguras que satisfacción, por ser la carrera eclesiástica una profesión de sacrificios, que sólo se mitigan con los entusiasmos de la vocación».

¿Cómo era Lobo? Quienes le conocieron en las distintas etapas de su vida le recuerdan como un hombre apasionado, «un gran corazón sin freno».17 más propenso a la acción que a la contemplación, aunque trataba de meditar sobre los acontecimientos de su vida y de la sociedad que le rodeaba. Félix Verdasco, alumno del Seminario de Madrid mientras Lobo era profesor, dice que era «hombre recio, buen talento y exaltado corazón».18

Tras varios meses de roces con el párroco, la falta de entendimiento y el choque de caracteres motivaron la salida de Lobo de San Pedro el Real. La primera dificultad surgió en enero de 1928. El párroco y Lobo escribieron al Vicario general de la diócesis. Aquél decía que su coadjutor llevaba tres meses sin presentar las cuentas de los pagos de la parroquia, algo que le competía. Lobo protestaba por la conducta despótica del párroco. ${ }^{19} \mathrm{La}$ cosa se solucionó en

${ }^{14}$ Cfr. José Luis González Gullón, El clero en Madrid durante la Segunda República, Pamplona, Tesis Doctoral 2007, p. 106.

${ }^{15}$ Cfr. Título de Doctoris gradu adipiscendo in Jure Canonico apud Pontificiam Universitatem Toletanam, 5-VII-1927, en AHDM, Personal Antiguo, Legajo 23, Expediente personal de Leocadio Lobo Canónigo.

${ }^{16} A B C, 12-$ VI-1926.

${ }^{17}$ La Vanguardia Española, 1-IV-1964. El artículo está firmado por Manuel Aznar.

${ }^{18}$ Félix Verdasco, Medio siglo de vida religiosa matritense. 1913-1963, Aldus, Madrid 1967, p. 95.

${ }_{19}$ Cfr. Oficio de Felipe Martínez Tercero al Vicario General Francisco Morán, Madrid, 20-I-1928, 22-I-1928 y 7-II-1928; Oficio de Leocadio Lobo Canónigo al Vicario general, Madrid, 30-I-1928, en AHDM, Personal Antiguo, Legajo 23, Expediente personal de Leocadio Lobo Canónigo. 
unos días gracias a la mediación del obispado, pero la tensión entre los dos sacerdotes se mantuvo.

En septiembre, saltaron de nuevo las chispas. Esta vez el motivo fue que Lobo no había acudido un domingo a la misa que tenía que celebrar a las diez de la mañana, obligando a suspenderla ante el asombro de los fieles. El párroco se quejó al Obispo. Lobo, por su parte, también escribió al prelado madrileño para manifestar que creía que todo era «obra de espíritu de venganza, del que tantas pruebas estoy recibiendo»..$^{20}$ Volvieron las aguas a su cauce, pues los problemas eran personales, pero, tras esto, Lobo tomó la resolución de buscar otro lugar donde ejercer su ministerio.

Un año más tarde, el 10 de julio de 1929, Bonifacio Sedeño de Oro, párroco de San Ginés de Madrid, comunicaba al obispado que Leocadio Lobo había tomado posesión como coadjutor primero -también llamado teniente mayor- de la parroquia. ${ }^{21}$ Era otro ascenso, que llevaba consigo beneficios económicos. Percibía algo más de 3.800 pesetas anuales, dinero suficiente para vivir dignamente y para enviar el sobrante a su familia. Además regresaba al centro de Madrid, a escasos pasos de la Puerta del Sol.

En esta época Leocadio había alcanzado un buen estatus dentro del clero, tanto por sus relaciones con la autoridad, como por su adscripción a diversas asociaciones católicas de la diócesis: pertenecía a la Asociación de Estudiantes Católicos de Magister ${ }^{22}$ y a la junta directiva de la Asociación Diocesana del Clero de Madrid-Alcalá. ${ }^{23}$ Era, en definitiva, uno de los hombres en los que se apoyaba el obispado para fomentar la relación entre los sacerdotes y para la cristianización de la sociedad.

Entre mayo de 1929 y junio de 1930, Leocadio Lobo colaboró regularmente con Las Migajas, la hoja parroquial de Nuestra Señora de las Angustias de Madrid. La publicación quincenal tenía catorce páginas, y en ella escribían algunos sacerdotes conocidos del párroco. Lobo publicó columnas de opinión sobre temas sociales y después pasó a cultivar la sección «Liturgia». Estos escritos interesan por ser los primeros en los que Leocadio plasmó sus ideas sobre la fe cristiana y su implantación en la sociedad. Sus comentarios litúrgicos trataban de acercar los misterios de la fe al pueblo y huían de todo formalismo. La fe debe vivirse interiormente, decía Lobo, porque, en caso contrario, «conviértese en-

\footnotetext{
20 Oficio de Leocadio Lobo Canónigo al Obispo de la diócesis de Madrid-Alcalá, Madrid, 20-IX1928, en AHDM, Personal Antiguo, Legajo 23, Expediente personal de Leocadio Lobo Canónigo.

${ }^{21}$ Cfr. Oficio de Bonifacio Sedeño al Secretario de Cámara y Gobierno del Obispado, Madrid, 10VII-1929, en AHDM, Personal Antiguo, Legajo 23, Expediente personal de Leocadio Lobo Canónigo.

${ }^{22}$ Cfr. ABC, 27-IV-1929.

${ }^{23}$ Cfr. Leopoldo Euo GaraY, Circular, 8-XII-1929, en BOOMA, n. 1501, 20-XII-1929, pp. 449451. En esas páginas pueden verse los Estatutos de la Asociación.
} 
tonces en juego de niños, ritualismo huero e incomprensible. Solamente así se explica que aún las ceremonias más tiernas y las espléndidas manifestaciones de nuestro culto nada digan a muchos que, con el alma fría e indiferente, las contemplan». ${ }^{24}$ Frente a «la indiferencia y cansancio del pueblo fiel», 25 abogó porque se tradujera la liturgia al castellano, de modo que resultara más accesible a los fieles.

En estos textos, Leocadio Lobo se movió dentro de los parámetros tradicionales de la cultura católica. Subrayó el papel del sacerdote como dirigente del pueblo, pues tenía experiencia de la reacción favorable de la feligresía cuando los párrocos eran celosos y activos. En una ocasión, después de haber asistido a un encuentro en las Angustias comentó: «me convencí, lleno de gozo, de que pueblo cristiano secunda, generoso, las iniciativas de su párroco». ${ }^{26}$

Insistió además en la necesidad de llegar a la gente humilde, a la que contemplaba con especial deferencia. Al asistir a una procesión, Leocadio se alegró, pues «junto al rico tapiz elegante y señorial, y cerca del pañuelo bordado, rico en flecos y colores, se veía la humilde colcha de algodón, exquisito tributo de los pobres, el más agradable, quizá, a los ojos del Señor». ${ }^{27}$ Fue probablemente en las Angustias donde el político Ángel Ossorio encontró a Lobo junto a unos pobres, sentado «a tomar el sol con mujeres desgreñadas y chiquillos mocosos, departiendo con todo aquel mundo sucio de cuerpo y a oscuras el alma para procurar un poco menos de dolor y un poco más de cultura». ${ }^{28}$

Un aspecto relevante, propio de la cultura católica del momento, era la imperiosa necesidad de que los católicos estuviesen unidos frente a dos grandes males: el liberalismo y el comunismo. Lobo plasmará esta idea con una anécdota. En abril de 1929 acompañó al jesuita padre Pulgar, quien recibió la visita de un grupo de jóvenes católicos de Alemania. Después escribió en Las Migajas: «Luchan, pero no importa. El racionalismo protestante y las ideas perturbadoras del socialismo comunista y anarquizante les hizo formar el «frente único», como defensa de los más altos intereses de la Religión y de la Patria». ${ }^{29} \mathrm{La}$ comparación con el caso español surgió inmediatamente: «También aquí -pensé-, también en España, dentro de poco, serán millones los corazones juveniles que se agrupen alrededor de Cristo». 30

\footnotetext{
${ }^{24}$ Leocadio Lobo CANónIGo, Las Migajas, 7-IX-1929, p. 8.

${ }^{25}$ Leocadio Lobo CANóNIGO, Las Migajas, 7-VIII-1929, p. 8.

${ }^{26}$ Leocadio LoBo CANóNIGo, Las Migajas, 7-V-1929, p. 8.

27 Ibidem.

28 «La oración del padre Lobo», en La Vanguardia, 22-XII-1938.

${ }^{29}$ Leocadio Lobo CANÓNIGO, Las Migajas, 22-VI-1929, p. 8.

${ }^{30}$ Leocadio Lobo CANóNIGo, Las Migajas, 22-VI-1929, p. 9.
} 
La Segunda República llegó cuando Leocadio Lobo estaba en un momento de madurez. Con cuarenta y cuatro años, tenía a sus espaldas una amalgama de experiencias: nacimiento humilde, estudios y doctorado en Derecho canónico, enseñanza y publicaciones sobre liturgia, estancias en Marruecos y en Alemania $^{31}$ y una gran sensibilidad social marcada por la formación recibida y por la experiencia parroquial diaria. Sin duda, Leocadio era un hombre lleno de ímpetu, de carácter fuerte, que no se doblegaba ante su deseo de transmitir el Evangelio y, a la vez, sabía hacer amigos. Durante la República se manifestarán muy vivamente su acción pastoral y su pensamiento político.

Llama la atención su asidua dedicación a las tareas pastorales encomendadas en la parroquia de San Ginés. No es posible saber cuánto tiempo dedicó a oír confesiones o a atender las prácticas devocionales. En cambio, está registrada la administración de tres sacramentos en los libros parroquiales: en 1931, Leocadio Lobo ofició 162 funerales, 74 matrimonios y 5 bautizos. Estas cifras se mantuvieron durante la República. Por ejemplo, en 1935 celebró 116 funerales, 64 matrimonios y 3 bautizos..$^{32}$ Que Lobo oficiase un funeral cada tres días es significativo por la abnegada preparación de cada acto, por el conocimiento que obtuvo de las familias del barrio y por el contacto con el dolor.

Aparecieron entonces algunas ideas políticas que más tarde eclosionarán en sus escritos y declaraciones durante la Guerra Civil. Según el diario integrista El Siglo Futuro, a principios de 1932 Leocadio Lobo proclamó en un sermón su «espíritu liberal y convicción republicana». ${ }^{33}$.El origen humilde, la experiencia pastoral con familias necesitadas y el contacto con los católicos liberales como Ángel Ossorio habían forjado esta opción política y cultural en su mente. ${ }^{34}$ Leocadio entendía que sus ideales sociales se acomodaban mejor a la República. Nunca aceptó, en cambio, algunos de sus postulados esenciales, como la libertad de conciencia y la cambiante cultura de la Modernidad. Mantuvo la concepción tradicional católica recibida, según la cual una fe única da lugar a respuestas culturales únicas.

En esos momentos, los católicos republicanos eran una minoría desprovista de masas pero presente en la vida política española. Uno de sus axiomas era la aceptación del Estado no confesional que con tanta celeridad implantó la Se-

${ }^{31}$ En una ocasión recuerda su visita a Berlín y Munich: cfr. Leocadio LoBo CANónigo, Las Migajas, 7-X-1929, p. 9.

32 Cfr. Libro de Bautismos, n. 63 (1928-1936); Libro de Defunciones, n. 31 (1930-36); Libro de Matrimonios, n. 27 (1929-36), del Archivo de la Parroquia de San Ginés.

${ }^{33}$ El recorte del periódico se encuentra dentro de AHDM, Personal Antiguo, Legajo 23, Expediente personal de Leocadio Lobo Canónigo. Aunque no está fechado, parece que corresponde a 1932 porque en el anverso se alude a la discusión del Estatuto catalán.

34 Parece que también trató a Luigi Sturzo cuando éste visitó España en 1934: cfr. Estampa, 15-IX1934 y El Liberal, 6-VI-1937. 
gunda República. El catolicismo republicano trataba de conciliar la fe tradicional con la cultura moderna, algo que no era sencillo debido a la autonomía de la conciencia propugnada por la Modernidad. Un peligro evidente para estos católicos era que su fe podía quedar relegada al sentimiento o al fideísmo, alejándola de la razón. ${ }^{35}$ En cambio, les resultaba más sencillo que a otros católicos diferenciar la «sumisión que debemos a la Iglesia en materia de fe y costumbres» ${ }^{36}$ del «propio juicio en materias sometidas a la discusión humana y a las disputas de los hombres».

Aceptar el régimen republicano y abrazar las ideas del catolicismo liberal llevaba consigo un enfrentamiento intelectual con la mayoría del clero y de los fieles, formados en un ambiente antimodernista y en una cultura tradicional, que se apoyaba más en las estructuras -reales o deseadas- que en la sociedad. Los católicos tradicionales censuraban sistemáticamente a quienes convivían con la República. Alegaban motivos que, si bien no eran las razones de fondo sobre qué principios religiosos, culturales y políticos debían dirigir la sociedad, los juzgaban convincentes: el ahogo de la Iglesia tras la aprobación de la Constitución de 1931 y las leyes que la aplicaron durante los gobiernos de Manuel Azaña, la inútil colaboración política de los católicos posibilistas con la República en los años 1933-1935, y el creciente desorden social. ${ }^{37}$

Durante la República, Leocadio Lobo no descuidó en ningún momento sus múltiples tareas pastorales ni su relación con muchos amigos sacerdotes. Por ejemplo, en la primavera de 1935, Xavier Zubiri, sacerdote y catedrático de historia de la filosofía, presentó ante el obispado de Madrid una petición de dispensa de las obligaciones derivadas de su condición sacerdotal. De los ocho testigos, cinco eran sacerdotes: Leocadio Lobo, José Gallegos Rocafull, canónigo lectoral de Córdoba, Francisco Romero Otazo, catedrático de la Universidad Central, el agustino José López Ortiz, profesor de la Universidad de Santiago, y Ángel Sánchez Cámara, encargado de la parroquia de Ciempozuelos. Zubiri recibió la solicitada dispensa. ${ }^{38}$

El pensamiento republicano de Leocadio se acentuó esos años. Según Cesáreo Barroso, ecónomo del pueblo de Humanes de Madrid, Lobo acabó por afiliarse «a Izquierda Republicana, y fue utilizado por Azaña, del que decía que

\footnotetext{
${ }^{35}$ Cfr. Gonzalo Redondo, Historia de la Iglesia en España. 1931-1939, t. I, «La Segunda República (1931-1936)», Madrid, Rialp. 1 993, p. 358.

36 Leocadio Loвo, «Ya era hora», en El Liberal, 13-VI-1937.

${ }^{37}$ Cfr. Manuel Álvarez TARdío, Anticlericalismo y libertad de conciencia. Política y religión en la Segunda República Española (1931-1936), Madrid, Centro de Estudios Políticos y Constitucionales 2002, pp. 363-366.

38 Cfr. Jordi Corominas; Joan Albert Vicens, Xavier Zubiri. La soledad sonora, Madrid, Taurus 2006, p. 322.
} 
era un político extraordinario y el que iba a salvar a España». ${ }^{39}$ Barroso recordaba que «el día 13 de junio del año 1936 fue a predicar a las fiestas de Griñón. Allí estábamos con él cuatro o cinco sacerdotes, y nos hizo una apología tan tremenda de Azaña, que nos invita a afiliarnos a Izquierda Republicana. Y después de discutir con él, disuadiéndole del matiz izquierdista y anticlerical del Partido, le dije: -Vd. ahí no me encontrará jamás; en ningún partido, pero ahí, jamás».

\section{La Guerra Civil (1936-1939)}

El Alzamiento Nacional de julio de 1936 fue inicialmente un golpe de Estado militar de carácter republicano, anticomunista y nacionalista. Esta concepción de España incluía la defensa de los valores católicos que -según los sublevados- habían contribuido con gran eficacia a lo largo de los siglos a configurar el orden tradicional. ${ }^{40}$ Los católicos españoles recibieron el golpe militar con cierta sorpresa, pero enseguida muchos lo secundaron porque compartían los valores defendidos por los golpistas, entre los que se contaban el restablecimiento del orden social y la libertad de la Iglesia.

En la zona republicana estalló una revolución social que, además, trató de eliminar a la Iglesia, sobre todo a los obispos y a los curas. La violencia contra el clero era necesaria, argumentaban los más radicales, porque si se deseaba ardientemente un orden social distinto hacía falta destruir el existente. La mutación cultural violenta y revolucionaria incluía la eliminación sistemática de aquéllos que representaban la tradición con la que era necesario romper.

La persecución religiosa fue un motivo esencial para que muchos católicos españoles se opusieran al Gobierno del Frente Popular en los primeros días de la guerra. A esta razón se unieron otras de carácter político -sobre todo la legislación y la violencia anticlericales de la Segunda República-, y de orden cultural, como fue la identificación -ficticia o real- de la Iglesia con la parte de la sociedad. ${ }^{41}$

Hubo también católicos, y entre ellos estuvo Leocadio Lobo, que entendieron que era precisamente su fe la que les obligaba a permanecer fieles a la República porque debían respetar el poder constituido y porque no podían aceptar la ideología de los militares sublevados. ${ }^{42}$ Ahora bien, la persecución a la Igle-

\footnotetext{
39 «Cesáreo Barroso Nieto, testimonio al autor», en José Luis AlfaYA, La diócesis de Madrid-Alcalá durante la guerra civil: 1936-1939, Pamplona, Tesis Doctoral 1987, p. 245. Durante la Guerra Civil, Lobo negó haber estado afiliado a un partido político: El Liberal, 28-V-1937.

${ }^{40}$ Cfr. Gonzalo Redondo, Historia de la Iglesia en España. 1931-1939, t. I, op. cit., p. 514.

${ }^{41}$ Cfr. Anthony Beevor, La Guerra Civil española, Barcelona, Crítica 2005, p. 120.

${ }^{42}$ Los asesinatos de inocentes en ambos bandos, la falta de comunicación entre ellos, y la propaganda de cada sitio hicieron que pronto muchos pensasen que «todos y sólo los buenos estaban de un
} 
sia exigió a estos católicos republicanos respuestas convincentes: ¿por qué apoyaban a un Estado en el que había una persecución asesina y calculada contra los mismos católicos? Y, para los sacerdotes, la pregunta era todavía más lacerante: ¿por qué sostenían un sistema que permitía el asesinato de sus compañeros, colegas de trabajo y amigos?

En el caso del clero -exceptuando el caso de Euzkadi y Cataluña- fueron pocos los curas que mostraron públicamente su adhesión a la causa republicana durante la Guerra Civil. Precisamente su singularidad hizo que nombres como Leocadio Lobo, José Manuel Gallegos Rocafull, ${ }^{43}$ Maximiliano Arboleya, ${ }^{44}$ Enrique Vázquez Camarasa, ${ }^{45}$ Jerónimo García Gallego, ${ }^{46}$ o Hugo Moreno López ${ }^{47}$ apareciesen con frecuencia en la prensa. ${ }^{48}$ Este artículo se ciñe lo más posible al pensamiento y a la actuación de Lobo, sin olvidar que mantuvo contacto e intercambio de ideas con otros sacerdotes -de modo especial con Gallegos Rocafull-, y que en ocasiones firmó declaraciones conjuntas con otros presbíteros e intelectuales. El estudio de su pensamiento resulta interesante porque en algunas posturas demostró equilibrio o fue profético, pero también porque sostuvo posturas propagandísticas, o incluso hizo afirmaciones polémicas y exacerbadas.

\section{Posicionamiento político sobre la Guerra}

La Guerra Civil comenzó en Madrid el 18 de julio. Como los otros 2.000 sacerdotes seculares y regulares que residían en la capital, Leocadio Lobo reaccionó en la medida en que le llegaban noticias o rumores de ataques contra

\footnotetext{
lado y del otro no había más que malos» (José M. GALlegos Rocafull, La pequeña grey. Testimonio religioso sobre la Guerra Civil española, Barcelona, Península 2007, p. 17).

${ }^{43}$ Canónigo lectoral de Córdoba (cfr. José M. Gallegos Rocafull, La pequeña grey..., op. cit.).

${ }^{44}$ Sindicalista y deán de la Catedral de Oviedo (cfr. Domingo BenAvides GómEZ, El fracaso social del catolicismo español. Arboleya Martínez, 1870-1951, Barcelona, Nova Terra 1973).

${ }^{45}$ Magistral del Cabildo de Madrid. En septiembre de 1936 intentó, sin éxito, que el general Moscardó entregara el Alcázar de Toledo; poco después pasó al exilio en Francia: cfr. Expediente personal de Enrique Vázquez Camarasa, Archivo Central de Curia de la Archidiócesis de Madrid (en adelante ACCAM), XV, A v 2.

${ }^{46}$ Canónigo de Osma. Fue suspendido a divinis poco antes de las elecciones de febrero de 1936 (cfr. Expediente personal de Jerónimo García Gallego, en AHDM, Personal Antiguo, Legajo 16).

${ }^{47}$ Columnista del Heraldo de Madrid que escribía bajo el pseudónimo «Juan García Morales» (cfr. Expediente personal de Hugo Moreno López, ACCAM, A m 12.1).

${ }^{48}$ En ocasiones, publicaron artículos de la mano de intelectuales o políticos católicos como Ángel Ossorio y Gallardo; José Bergamín, editor de Cruz y Raya; Enrique Moreno, profesor en la Universidad de Oxford; o José María Semprún, catedrático de la Universidad Central y embajador de España en La Haya durante la guerra.
}

Hispania Sacra, LXII

125, enero-junio 2010, 267-309, ISSN: 0018-215-X 
las iglesias y sus ministros. Pronto quedó clara la disyuntiva que tenía el clero si deseaba seguir viviendo: esconderse o huir. Las cifras hablan por sí solas: 306 sacerdotes seculares en Madrid capital (el 27,8\% del total de los residentes) y 398 religiosos (el 39,8\%) fueron asesinados durante la Guerra Civil. ${ }^{49}$ De los dieciséis sacerdotes que integraban la plantilla de San Ginés, la parroquia donde trabajaba Leocadio Lobo, siete fueron asesinados; uno de ellos, Sebastián de la Peña, había compartido su trabajo pastoral con Lobo en numerosas ocasiones. ${ }^{50}$

El 95,1\% de esos asesinatos de sacerdotes en Madrid se produjo durante el segundo semestre de 1936. Fueron los meses del terror rojo, de las checas y las sacas, meses sin legalidad alguna, en los que cabía la duda sobre la actitud de un Gobierno que, aunque estaba desbordado por los acontecimientos y no alentó los crímenes, permitió o al menos no deploró públicamente el asesinato de clérigos, los asaltos a iglesias y la suspensión del culto religioso. En cambio, a partir de enero de 1937, los asesinatos de eclesiásticos fueron extraordinarios y se produjeron habitualmente después de haber seguido una causa jurídica.

Leocadio Lobo se mostró desde el primer momento fiel al Gobierno del Frente Popular. Se reunió con algunas autoridades políticas y militares a las que manifestó su ideología republicana. Con todo, no se libró del terror en los primeros días de la guerra: «En cuarenta y ocho horas lo detuvieron cuatro veces y una de ellas lo llevaban de paseo [para ser asesinado] a la pradera de San Isidro cuando providencialmente pasó por una casa republicana donde estaba seguro de que responderían por él». ${ }^{51}$

Dadas las circunstancias, dejó de celebrar misa y se vistió con un traje negro de alpaca. Su singularidad -un cura republicano-, pronto fue conocida y respetada por los milicianos. Lobo utilizó este estatus para moverse por Madrid, tratando de defender algunos bienes pertenecientes a la diócesis. El 20 de julio, acudió al palacio episcopal, donde estaban también las oficinas de la curia diocesana, y consiguió que los milicianos no lo quemasen. Lo mismo hizo con la Capilla del Obispo, en la plaza de la Paja, salvando algunas joyas y piezas de arte. 52

${ }^{49}$ Según mi investigación realizada en AHDM y ACCAM con 721 expedientes personales de sacerdotes residentes en Madrid en 1936, y con la bibliografía sobre el particular, especialmente José Luis AlfaYa, Como un río de fuego. Madrid, 1936, Madrid, Ediciones Internacionales Universitarias 1998 (segunda edición), pp. 104-105.

${ }^{50}$ Cfr. José Luis Alfaya, Como un río de fuego..., op. cit., pp. 285-309.

51 José M. Gallegos Rocafull, La pequeña grey..., op. cit., p. 10.

52 Cfr. Salvador MuÑoz Iglesias, «Cuarenta años para un obispo: Don Leopoldo Eijo Garay», Cuadernos de Historia y Arte. Centenario de la Diócesis de Madrid-Alcalá, 2, Madrid, Arzobispado de Madrid-Alcalá 1986, p. 81. 
La propaganda republicana se sirvió de él. Como ya habían hecho otros sacerdotes e intelectuales -el presbítero Hugo Moreno López, el editor de la revista Cruz y Raya José Bergamín o el político Ángel Ossorio-, Lobo habló el 20 de septiembre desde los micrófonos de la emisora del Partido Comunista en Madrid. Comenzó su intervención subrayando su estado clerical: «Soy sacerdote católico y español. Estoy en comunicación con la Santa Sede y con mi prelado, hoy ausente de Madrid. Jamás he recibido amonestaciones ni aviso por opiniones ni doctrinas». ${ }^{33}$ Dijo también: «Confieso y afirmo que antes que nada soy hijo del pueblo, que amo al pueblo con todo mi corazón, que con él y por él estoy dispuesto a dar mi vida. La religión católica que profeso me manda amarle, porque la religión no es de castas ni de clases».

Nada dijo de la persecución religiosa contra el clero. Acusó a los nacionales de ser los únicos responsables de una guerra que el pueblo ni había provocado ni había querido. Denunció que hubiesen amalgamado los valores propios de la nación española y del catolicismo con la violencia, el fascismo y el recurso a tropas musulmanas. Criticó sobre todo el programa social de la zona nacional que, bajo el escudo de la palabra «orden», perpetuaba un tradicionalismo cultural que ni ayudaba a resolver la situación de los más necesitados ni acogía a los grupos sociales nuevos, como los trabajadores industriales: «Personas que asimismo se llamaban de orden y también clases de orden y partidos políticos de orden y Prensa de orden; se habló del "orden establecido", y acorazándose y defendiéndose contra los trabajadores, se les llamó con infinito desprecio "enemigos del orden". "Que todo siga igual era la suprema aspiración de los confortablemente instalados en la vida, a quienes poco o nada preocupaba la existencia de los desheredados"».

Esos obreros eran los más necesitados, los que había que apoyar, aunque tal cambio exigiese un nuevo programa cultural y económico: «¿Que las masas se rebelan contra un sistema económico absurdo y brutal? Pues sabed que yo estoy a su lado, porque a su lado está la Iglesia desde hace mucho tiempo, aunque nuestros egoísmos hayan olvidado las enseñanzas de los papas».

Rechazó la ideología comunista. Ahora bien, mientras dejaba de lado a los nacionales por ser sus enemigos políticos, trataba de convertir a la fe católica a los partidarios del comunismo: «vuestra obligación y la mía es amarles más, buscarles por los senderos y caminos de la vida, decirles que todas sus legítimas y justas aspiraciones son cristianas».

${ }^{53}$ El Cantábrico, 24-IX-1936. El discurso apareció publicado parcialmente en ABC, 22-IX-1936, y en Catholics and the Civil War in Spain, London, The National Council of Labour Transport House 1936, pp. 6-9.

Hispania Sacra, LXII

125, enero-junio 2010, 267-309, ISSN: 0018-215-X 
Unos días más tarde, el 12 de octubre, apareció un manifiesto titulado Palabras cristianas.$^{54}$ Había sido redactado por José Manuel Gallegos Rocafull, y lo firmaban también Leocadio Lobo y Enrique Monter. ${ }^{55}$ Gallegos y Lobo habían recibido el visto bueno del Encargado de Negocios de la Santa Sede, Silvio Sericano, y del claretiano Juan Postius, que residía entonces en el palacio de la nunciatura. Recogían, sin comentarios, los textos del magisterio eclesiástico que refrendaban estas tres ideas: «la rebelión contra el gobierno legítimo es ilícita»; «son justas y necesarias hondas reformas sociales»; y «ningún partido político se identifica con el catolicismo, y el fascismo en sus más fundamentales aspectos está en pugna con él». El manifiesto acababa pidiendo oraciones por la paz y por la reanudación del culto.

\section{Propagandista en Europa}

A mediados de octubre, Leocadio Lobo fue convocado, junto a José Manuel Gallegos Rocafull, por el ministro de Estado, Julio Álvarez del Vayo. Llegados al ministerio, Álvarez del Vayo les comunicó que Ángel Ossorio, embajador de España en Bruselas, había organizado un congreso de católicos antifascistas, y deseaba que los dos asistiesen. ${ }^{56}$ Recibieron pasaportes y pasajes para el viaje, y salieron de Madrid el 27 de octubre. ${ }^{57}$

De paso por París, saludaron a Xavier Zubiri. ${ }^{58}$ Llegados a Bruselas, se alojaron en la embajada española. Ossorio les comunicó que finalmente no se celebraría el Congreso, pero les ofreció la posibilidad de dar a conocer la situación de España y de recaudar fondos para ayudar a la población necesitada.

Justificando sus intervenciones como una respuesta a unas declaraciones del Obispo de Tenerife, Albino González, a favor de las tropas de Franco, Lobo y Gallegos pronunciaron sendas conferencias sobre «la rebelión Militar vista desde Madrid» el 7 de noviembre en la Casa de España de Bruselas. ${ }^{59}$ Acudieron

\footnotetext{
${ }^{54}$ Está reproducido en José M. Gallegos Rocafull, La pequeña grey..., op. cit., pp. 211-217.

55 Monter había sido capellán de la Beneficencia provincial en Madrid. Años más tarde, este sacerdote se retractó por haber firmado el manifiesto (Expediente personal de Enrique Monter Santamaría, ACCAM, XV, A m 11).

56 Cfr. José M. Gallegos Rocafull, La pequeña grey..., op. cit., pp. 33-34.

57 Cfr. Leocadio Lobo a mons. Michael Ready, Los Angeles, 29-III-1939, en The American Catholic History Research Center and University Archives, Washington (en adelante ACUA), National Catholic Welfare Conference, Box 16 Folder 8 (Lobo, Leocadio).

58 Cfr. Jordi Corominas; Joan Albert Vicens, Xavier Zubiri..., op. cit., p. 395.

${ }^{59}$ Cfr. Deux prêtres espagnols parlent de la Tragédie de l'Espagne, Anderlecht, S. Hiernaux 1936. El texto también apareció en castellano: 3 grandes católicos os hablan: Ossorio y Gallardo, Leocadio Lobo, José Ma. Gallegos, Santiago de Chile, Comité Pro España Republicana 1936. Lobo y Gallegos hicieron suyos algunos textos publicados por José María Semprún Guerra en «La question d'Espagne inconnue», Esprit. Revue Internationale 50 (1-XI-1936) pp. 291-319.
} 
ciento treinta personas. Según el representante de Franco en Bruselas eran «unos cuantos mineros españoles de Charleroi, algunos pelotaris de Jai Alai de Bruselas, «nacionalistas vascos», y los restantes la media docena de españoles de algún viso que, como informé a V.E., siguen fieles al pseudo Gobierno de Madrid». 60

Tras las presentaciones, cuando comenzó a hablar Lobo, un grupo de veinte personas se puso a gritar a favor de Franco y de la España nacional. De los gritos se pasó a las manos. La policía tuvo que desalojar a los alborotadores ${ }^{61}$ Con emoción, Leocadio siguió adelante afirmando que el pueblo español se había levantado "parce qu'il a voulu défendre sa juste cause». ${ }^{62}$ Recordó más que el motivo religioso de la Guerra Civil no era el único ni el más importante. La lucha se había producido porque el pueblo deseaba crecer socialmente, rebelarse contra el concepto de «orden»: «que tout doit rester comme par le passé, c'est l'aspiration de tous ceux qui sont confortablement installés dans la vie».

Sus palabras fueron polémicas. Defendió a la República, atacó a los sublevados y alabó a los comunistas. Explicó la violencia en la zona republicana: «les communistes ont affirmé à différentes reprises qu'ils n'aspirent pas en ce moment à la République soviétique, mais simplement au maintien de la République démocratique». Había habido excesos aislados, pero los comunistas se habían comportado generalmente «avec un sens remarquable de la responsabilité et de la prudence». El Gobierno no era responsable de la violencia ni del asesinato de inocentes: «ces faits se produisent malgré le pouvoir public et le régime, en aucune manière comme sa forme d'expression ou d'action». Por tanto, no podían imputarse al pueblo esos males, debidos más bien «à la racine tragique de notre tempérament et de notre constitution sociale naturelle».

Los dos bandos habían cometido atrocidades, pero la responsabilidad moral de la barbarie residía en los que habían desencadenado la guerra. Los sublevados se habían alzado contra el poder establecido: «ceux qui, au lieu d'être ses gardiens, se sont fait ses bourreaux». Esos hombres habían acudido "à la sédition et à la violence, à l'infidélité et aux perjures, à l'utilisation des Maures et des mercenaires, à la trouble complicité des despotiques tyrannies». A través de la fuerza militar, las clases conservadoras «ont tenté et elles ont réalisé, en partie, l'union entre les catholiques d'une organisation de type conservateur et une réaction d'origine bourgeoise».

\footnotetext{
${ }^{60}$ Anexo de carta de José Antonio Sangróniz al Cardenal Isidro Gomá, Salamanca, 17-XI-1936, en Archivo Gomá: documentos de la guerra civil, Documento 1-193.

${ }^{61}$ Aunque varían algunos matices, Gallegos recordaba el incidente de modo semejante: José M. GaLlegos Rocafull, La pequeña grey..., op. cit., pp. 44-47.

62 «Causerie du Père Lobo. Ancien professeur au séminaire de Madrid», en Deux prêtres espagnols parlent de la Tragédie de l'Espagne..., op. cit., p. 3.

Hispania Sacra, LXII

125, enero-junio 2010, 267-309, ISSN: 0018-215-X
} 
Al día siguiente, Lobo y Gallegos Rocafull recibieron la noticia de que les esperaba el Cardenal de Bruselas, Jozef-Ernest van Roey. Los recibió Étienne Carton de Wiart, Obispo auxiliar, quien les amonestó para que dejaran de hablar en público en Bélgica ${ }^{63}$ Casi sin darles tiempo a cancelar los compromisos que tenían, la policía los localizó y los acompañó a la frontera. Se les expulsaba por razones políticas, pues las autoridades belgas deseaban evitar problemas con el Gobierno del general Franco y con la Santa Sede.

Las noticias de los encuentros y movimientos de Lobo y Gallegos circulaban por los despachos diplomáticos de Europa. Ernesto de Zulueta, representante del Gobierno de Franco en Bruselas, escribió a José Antonio Sangróniz, jefe del Gabinete Diplomático, contando pormenorizadamente la conferencia del día 7. Sangróniz escribió al Cardenal Gomá, y éste al Cardenal Pacelli. El Arzobispo de Toledo pedía que, debido a que los sacerdotes se dedicaban «en el extranjero a desvirtuar los fines del movimiento», 64 a un movimiento que, sostenido por el Ejército nacional, era la «única garantía hoy de la salvación de España, me permito insinuarle la conveniencia de por quien fuese se apliquen las correspondientes sanciones canónicas». La respuesta del cardenal Pacelli fue inmediata: se habían dado «sollecite ed opportune istruzioni all'Ecc.mo Nunzio Apostolico di Bruxelles, affinchè siffatte manifestazioni non abbiano a ripeter$s i » .65$ En la agenda de Gomá el «caso Lobo» estuvo siempre presente. No era para menos. En un momento de polémica vivísima, las ideas políticas, eclesiales y culturales del Cardenal chocaban frontalmente con las de Lobo.

Después de recibir varios informes negativos, el Obispo de Madrid-Alcalá, Leopoldo Eijo Garay, con decreto de su puño y letra, fechado en Vigo el 5 de diciembre de 1936, suspendió a divinis a Leocadio Lobo y le privó de su cargo de Teniente mayor de la parroquia de San Ginés. El motivo principal era su escandalosa actuación pública «pues tanto en artículos de prensa como en alocuciones por radio no sólo critica acerba e indisciplinadamente a la Jerarquía Católica y a su propio Ordinario excitando contra aquélla y contra éste el odio de la plebe por medio de calumnias e injurias, las cuales vierte también sobre los heroicos salvadores de España difamándolos, mientras él presta cuanta ayuda y defensa puede a los enemigos de la Iglesia y de la Patria, fomentando con ello la guerra intestina y la perturbación sacrílega y criminal

\footnotetext{
${ }^{63}$ Hay noticias de que dieron otra conferencia en un local llamado la «Brasserie Flamande»: Vicente CÁRCEL ORTí, La persecución religiosa en España durante la Segunda República (1931-1939), Madrid, Rialp 1990, p. 205.

${ }^{64}$ Isidro Gomá a Eugenio Pacelli, Pamplona, 27-XI-1936, en Archivo Gomá: documentos de la guerra civil, Documento 1-218.

${ }^{65}$ Eugenio Pacelli a Isidro Gomá, Ciudad del Vaticano, 4-XII-1936, en Archivo Gomá: documentos de la guerra civil, Documento 1-237.
} 
del orden». ${ }^{66}$ Por encontrarse en la zona republicana, Lobo no iba a conocer su situación canónica hasta 1939.

Desde Bélgica, Lobo y Gallegos regresaron a París. Allí se separaron sus caminos. Gallegos permaneció en la capital francesa y Leocadio siguió moviéndose por Europa, como explicó más tarde: primero fue «a Amsterdam, donde el Comité de Ayuda al Pueblo Español había preparado una entrevista con los periodistas. Me dirigí a Londres para hablar en un mitin de la Cruz Roja, cosa que impidió la Policía deteniéndonos en el aeródromo de Croydon». ${ }^{67}$ Con todo, «quizá fue más eficaz mi ausencia que mi discurso, por el movimiento de protesta que causó mi detención. En aquel acto se recaudaron tres mil libras para España.

«Obligado por la Policía regresé a Amsterdam, y de allí a París donde lanzamos el manifiesto que tanta ira provocó a Queipo de Llano. Di dos conferencias en los barrios obreros de Auberville y Saint-Denis, y salí de nuevo, para Holanda, donde estuve hasta el 24 de febrero, donde di conferencias privadas y celebré reuniones con los periodistas, intelectuales, etc.». El manifiesto a que alude Lobo apareció en la revista Esprit en el mes de enero, y fue reproducido por la prensa. ${ }^{68}$ Nueve católicos protestaban por «le bombardement, répété jour par jour, de notre Madrid chéri, capitale incomparable de la République Espagnole». ${ }^{69} \mathrm{El}$ escrito lamentaba que fuesen violadas «les lois les plus simples $d u$ droit des gens, qui ne respecte pas même la moindre partie des status universellement connus sur le ménagement de la population civile au cours d'une guerre». Insistía además en que la «responsabilité énorme incombe à ceux qui se sont faits les initiateurs de cette lutte fratricide, oubliant les commandements de la conscience et les exigences de la loi!».

Leocadio Lobo fue detenido en Holanda y, después de pasar por la Dirección de Seguridad, fue obligado a salir del país. Atribuyó esta nueva expulsión a los manejos del pro-nuncio de la Santa Sede. De nuevo en París, Lobo publicó un breve artículo en francés, traducido a otros idiomas, titulado Confesión..$^{70} \mathrm{Se}$

${ }^{66}$ Decreto, Vigo, 5-XII-1936, en Expediente personal de Leocadio Lobo Canónigo, ACCAM, XV, A 13. Poco después, en febrero de 1937, Gallegos también recibió la notificación de que el Obispo de Córdoba le había suspendido a divinis. Esta pena conllevaba la prohibición de celebrar sacramentos.

${ }^{67} \mathrm{ABC}$, 4-IV-1937.

68 «Un appel espagnol aux catholiques du monde entier», Esprit. Revue Internationale 52 (1-I1937) pp. 624-625. De los nueve firmantes, tres eran sacerdotes -Lobo, Gallegos y García Gallego- y el resto políticos o escritores: Ángel Ossorio y Gallardo, Claudio Sánchez Albornoz, José Bergamín, José María Semprún, José Carner y Eugenio Imaz. El escrito también apareció en El catolicismo en la España leal y en la zona facciosa, Madrid-Valencia, Servicio Español de Información 1937, pp. 27-28; y en La Vanguardia, 27-I-1937.

69 «Un appel espagnol aux catholiques du monde entier», Esprit. Revue Internationale 52 (1-I1937) p. 624.

70 Cfr. El Pueblo Manchego, 27-III-1937; Mirador. Setmanari de literatura, art i politica, 1-IV1937.

Hispania Sacra, LXII

125, enero-junio 2010, 267-309, ISSN: 0018-215-X 
encontró en la capital francesa con el Cardenal Verdier y con Mons. Chaptal, «quienes me reconocieron como sacerdote católico, concediéndome audiencia, demostrando vivo interés por conocer la situación de millones de españoles católicos en España republicana, dándome 500 francos para misas por el pueblo español, las cuales celebré en la capilla española, rue de la Pompe». ${ }^{71}$

En estos primeros meses de 1937 aparecieron dos folletos, uno de Leocadio Lobo y otro de José Manuel Gallegos, titulados respectivamente Primate and Priest $^{72}$ y Crusade or Class War? The Spanish Military Revolt. ${ }^{73}$ Ambos fueron editados por el departamento de prensa de la embajada de España en Londres: el idioma y el país habían sido elegidos por el Gobierno español con el fin de dar realce internacional a la postura de los sacerdotes.

Los escritos deseaban responder las ideas del primado de España, Cardenal Isidro Gomá. A finales de 1936, Gomá había publicado El Caso de España, su primer escrito sobre la Guerra Civil con carácter general. ${ }^{74}$ Debido al elevadísimo número de curas y de católicos asesinados, el Cardenal, con palabras típicas de su tradicionalismo cultural, reconocía en la guerra «un espíritu de verdadera cruzada en pro de la religión católica, cuya sabia ha vivificado durante siglos la historia de España». ${ }^{75} \mathrm{Y}$ definía qué entendía por tal cruzada: era una lucha contra un sistema negador de Dios, contra una civilización opuesta a Cristo: «la de Rusia, que no es más que una forma de barbarie, y la cristiana, de la que España había sido en siglos pasados honra y prez e invicta defensora». ${ }^{76}$

Esta postura iba a consolidarse entre la Jerarquía según pasaban los meses, sobre todo cuando apareció la declaración colectiva del Episcopado español el 1 de julio de 1937. En ella, los Obispos se adherían públicamente al régimen de Franco. ${ }^{77}$ Desde entonces, el drama de los católicos republicanos consistió en

\footnotetext{
${ }^{71}$ Leocadio Lobo a mons. Michael Ready, New York, 4-III-1939, en ACUA, National Catholic Welfare Conference, Box 16 Folder 8 (Lobo, Leocadio).

${ }^{72}$ Fr. Leocadio Lobo, Vicar of San Ginés, Madrid, Primate and Priest, London, Press Department of the Spanish Embassy in London 1937.

73 José Manuel Gallegos Rocafull, Canon of Cordova Cathedral, Crusade or Class War? The Spanish Military Revolt, London, Press Department of the Spanish Embassy in London 1937.

${ }^{74}$ Cfr. María Luisa Rodríguez AísA, El cardenal Gomá y la guerra de España. Aspectos de la gestión pública del Primado (1936-1939), Madrid, CSIC 1981, p. 125.

75 Isidro Gomá Tomás, El Caso de España, Pamplona, Diputación Foral de Navarra 1936 (segunda edición), p. 7. El término «Cruzada» no tenía la actual connotación negativa. Durante la Segunda República, por ejemplo, tuvieron gran desarrollo en Madrid los Cruzados de la enseñanza, asociación de fieles seglares que fundaba o subvencionaba escuelas católicas para asegurar la formación religiosa de los niños (Cruzados de la Enseñanza, en ACCAM, XVIII, A c 4).

76 Isidro Gomá Tomás, El Caso de España, op. cit., p. 7.

${ }^{77}$ Esta carta fue contestada por un anónimo «Group of Spanish Priest» en un folleto titulado Christ or Franco? An Answer to the Collective Letter which the Spanish Episcopate issued to the Bishops of the World, publicado en Londres en 1937.
} 
ver que casi todos sus pastores se habían puesto al lado y a favor de las ideas políticas y culturales de la España nacional, y que también la Santa Sede tendía más lazos diplomáticos con el Gobierno nacional.

Primate and Priest consta de 16 páginas. Es el escrito más largo que se conserva de Lobo. Tiene un prefacio firmado por E. M., iniciales que -según otras publicaciones de estos años- corresponden a Enrique Moreno Báez, profesor de literatura en la Universidad de Oxford. A continuación, Leocadio Lobo plantea dieciocho cuestiones y hace once afirmaciones que pueden resumirse en las siguientes:

A) La rebelión militar no puede justificarse porque se produjo contra el poder legítimo y porque está aliada con el fascismo y la Falange. La Iglesia no puede tomar partido por un bando, y menos el de los rebeldes, pues hay católicos del lado republicano. En definitiva, las autoridades eclesiásticas españolas han de tener «words of love and pardon, words of generosity and anxiety, cries torn from the Christian soul to call down curses on the war, and to sow peace among the combats».

B) La guerra actual nada tiene que ver con las guerras de religión de las épocas anteriores a la Revolución francesa. Es una guerra «essentially human, political and social». Y son esos aspectos sociales donde los eclesiásticos, según Lobo, tendrían que haber influido años antes: «If, instead of political activity in defense of anti-Christian capitalism, we had carried out a social program, approved and blessed by our hierarchy, the fate of Spain today would have been very different».

C) No puede hablarse de martirios de sacerdotes y religiosos sin tener antes en cuenta que muchos confundieron política y religión, permitieron que en la puerta de sus iglesias se vendieran periódicos contrarios al régimen republicano y patrocinaron organizaciones no democráticas. Además, también había víctimas clericales en la zona nacional.

D) Mantiene su deseo de estar con el pueblo, enseñando el Evangelio a los pobres. Expresa -y sin duda este es uno de los puntos más polémicos de su escrito debido a las matanzas- su «gratitude to the Militia and to the people for the noble way in which they have treated numbers of priests, religious and nuns in Madrid. I publicly thank all those who accompanied me (...) during the first three months of the rebellion».

E) Finalmente, declara que detesta la guerra. Pide al Papa que se pronuncie con palabras de amor y de paz para frenar la contienda. «I condemn all the crimes and the horrors of the war, I weep for the death of prelates, priests and religious, and I weep even more bitterly for the death of so many innocents, above all of the women and children». 


\section{Jefe de la Sección de Confesiones y Congregaciones religiosas}

El 3 de abril de 1937, Lobo estaba en Valencia, dando por concluido su periplo europeo. Quedaban atrás cinco meses de andanzas, conferencias, encuentros y desencuentros. El 6 de abril llegó a Madrid acompañado por el vicario de la iglesia de St. Clements de Londres y otros católicos ingleses. ${ }^{78}$ Ese mismo día, el vicario londinense y Lobo hablaron por la radio a través de un micrófono instalado en la Delegación de Propaganda y Prensa.

Era el segundo mensaje de Lobo desde el lejano mes de septiembre del año anterior. Lamentó la situación en Madrid: «después de cinco meses consagrados a la verdad de España, he recorrido hoy algunas de tus calles, y he sentido en mi alma el dolor de tu catástrofe» ${ }^{79} \mathrm{Y}$ reafirmó su vocación y su amor al pueblo español: «yo no entiendo cómo algunos católicos han podido sumarse a esta sublevación; yo no sé cómo se puede disparar contra el pueblo. Deberían caerse al suelo las armas y el corazón, antes de matar y haber matado un solo obrero español, cualquiera que fuera su ideología».

Leocadio Lobo llegaba a Madrid cuando el ministro sin cartera, Manuel de Irujo y Ollo, católico vasco, trataba de restablecer el culto en el territorio republicano y evitar que los comunistas controlasen por entero la vida de la República. Irujo llevaba tiempo protestando porque todas las iglesias estaban cerradas y muchos clérigos habían sido detenidos o fusilados sin juicio previo, rompiendo así la posibilidad de que los católicos viviesen pacíficamente dentro de la República ${ }^{80}$ A la vez, había más intereses en juego. Quería que la Santa Sede siguiese manteniendo contactos con el Gobierno republicano y no con el de Franco; intentaba borrar el perjuicio que la persecución religiosa había causado a la República, dentro y fuera de España; y trataba de dar cauce legal a unas actividades clandestinas, fundamentalmente la celebración de sacramentos, conocidas y toleradas, al menos en las grandes ciudades como Barcelona o Madrid ${ }^{81}$ A partir del 17 de mayo un nuevo Gobierno, presidido por Juan Ne-

\footnotetext{
78 Cfr. $A B C, 8-I V-1937$.

$79 A B C, 7-I V-1937$. Parte de esta alocución apareció publicada en el folleto Religión y fascismo. ¡Queman, roban y asesinan... en tu nombre!, publicado en junio de 1937 por el Comité Ejecutivo Nacional del Socorro Rojo en España.

${ }^{80}$ Para Gallegos, «la causa republicana estaba perdida desde el momento en que no permitió la convivencia de los leales con Cristo sacramentado. ¿Qué sería del mundo sin la Eucaristía? Es verdad que el gobierno pensó siempre que esa situación era insostenible, pero seriamente no trató de remediarla sino hasta el fin de la guerra, cuando creó la Comisaría de Cultos, en vísperas de la derrota final» (José M. Gallegos Rocafull, La pequeña grey..., op. cit., p. 9).

${ }^{81}$ Irujo sabía que «en Madrid algunos sacerdotes, amparados en un carnet facilitado por el Partido Comunista, ejercen su ministerio en privado» (Manuel de Irujo a Leocadio Lobo, Valencia, 1-IV-1937, en Archivo Manuel de Irujo -en adelante AMI-, 23, 1, 16).
} 
grín, aceptó escuchar la propuesta de política religiosa de Irujo, recién nombrado ministro de Justicia.

Los contactos entre Irujo y Lobo dieron a éste la confianza del ministro y su regreso como personaje público no sólo a la radio y a la prensa, sino también a las instituciones públicas. Lobo fue nombrado Delegado de la Junta de Protección del Tesoro Artístico. A partir de entonces, comenzó a recoger los archivos parroquiales - de las treinta parroquias de Madrid llegó a tener veintidós, evitando en algunos casos su destrucción-, así como ornamentos y objetos religio$\operatorname{sos} .^{82}$ Fue un programa que llevó a cabo en Madrid y en algunas provincias. ${ }^{83}$

A principios de mayo, el soldado Albino Jiménez recibió la orden de dejar el frente de guerra para ponerse a las órdenes de Leocadio Lobo, sirviéndole como taquimecanógrafo. Gracias a su testimonio, conocemos otras actividades desarrolladas por el sacerdote. La principal fue la búsqueda de presbíteros: si se quería restablecer el culto, hacían falta ministros que lo ejercieran. Para ello, el Gobierno exigía a los sacerdotes que aceptasen la legislación de la República en guerra; a cambio, les ofrecería custodia y la apertura paulatina de las iglesias.

Ese mismo mes, Lobo convocó a varios sacerdotes en el hotel Florida, lugar donde se alojaba. Les propuso que firmaran una declaración de adhesión al Gobierno republicano como paso previo a la restauración del culto. ${ }^{84}$ Recordaba un año más tarde que «in the name of the Government I offered my colleagues the necessary permits for opening further churches and chapels where Catholics might hear Mass freely». ${ }^{85}$ Le sorprendió conseguir una sola firma, la de Dimas Sigüenza, coadjutor de la parroquia de San Ramón, situada en el Puente de Vallecas. ${ }^{86}$

La disyuntiva entre colaborar con el Gobierno para restablecer la normalidad religiosa o seguir en la clandestinidad a la espera de un cambio político la había resuelto la mayoría del clero a favor de la espera. La colaboración era demasiado exigente. Si aceptaban el régimen republicano, implícitamente daban por concluida la afrenta del asesinato de sus compañeros y, al mismo tiempo, se posicionaban frente al Obispo de Madrid-Alcalá y sus representantes. Uno de

\footnotetext{
${ }^{82}$ Cfr. Leocadio LoBo, «Cómo respetó el pueblo el tesoro artístico eclesiástico», El Catolicismo en la España leal y en la zona facciosa, Madrid-Valencia, Servicio Español de Información 1937, p. 8.

${ }^{83}$ Lobo estuvo en Barbastro y en el monasterio del Pueyo con esa finalidad: A. DE CASTRo ALABARRÁN, La gran víctima. La Iglesia española mártir de la revolución roja, Salamanca, (sin editorial) 1940, p. 101; Carles Gerhard i Hortet, Comissari de la Generalitat a Montserrat (1936-1939), Montserrat, Publicacions de l'Abadia de Montserrat 1982, p. LIV.

${ }^{84}$ Cfr. Declaración de Albino Jiménez Fernández, Madrid, 16-VI-1939, en Expediente personal de Leocadio Lobo Canónigo, ACCAM, XV, A 13.

${ }^{85}$ Leocadio Loвo, Open Letter to the Editor of the «Times», Barcelona, junio 1938, en London School of Economics Archives, Coll Misc 0091/38.

${ }^{86}$ Cfr. Expediente personal de Dámaso Sigüenza, en AGCAM, XV, A s 7.
} 
los invitados a firmar el documento fue Cesáreo Barroso, ecónomo de Humanes de Madrid. Según recordaba años más tarde, ni siquiera acudió al encuentro porque el documento «era tan ambiguo, que suponía un rechazo de la Santa Sede o una especie de apostasía general. Yo conocía mucho a D. Leocadio Lobo y me llamó a mí junto a otros varios sacerdotes, para firmar el documento, a través de distintas personas conocidas de él. Y mi contestación fue que mientras durara la guerra no me entrevistaría con Lobo. (...) Pues bien, cuando nos negamos a firmar aquel documento, nos dijo: -así os extrañaréis que luego os asesinen». 87

El 31 de julio, el ministro Irujo presentó una propuesta para restablecer el culto público. Amparándose en el hecho de que de iure no había sido derogada la libertad de cultos, el Gobierno rechazó el proyecto. En realidad, los ministros temían que la reapertura de las iglesias llevase consigo una reacción adversa de políticos y de militares anticlericales, que se diese alas a los quintacolumnistas y que fuese aprovechada por la propaganda franquista para evidenciar que hasta ese momento el culto había desaparecido en la zona republicana. El Gobierno al menos llegó al acuerdo verbal de que «no existe inconveniente alguno para practicar el culto religioso en capillas privadas, siempre que, tanto las mismas como sus ministros, sean autorizados previamente por el Departamento de Justicia». ${ }^{88}$ Irujo aprovechó esta aprobación para presentar un nuevo proyecto, esta vez de culto privado, que fue sancionado por el Consejo de ministros el 7 de agosto. Durante los meses siguientes adoptó medidas encaminadas a conseguir una normalización religiosa, como la protección jurídica a los sacerdotes frente a denuncias, o la protección de edificios y objetos religiosos. ${ }^{89}$

Todos estos intentos fracasaron por falta de voluntad. Ninguna de las dos partes lo quiso. Por un lado, la mayoría de los sacerdotes deseaba que el culto fuese público y universal, no reducido a unos pocos sitios o bajo sospechas de que era un acto de propaganda a favor de la República. Además, les faltaba el apoyo de la autoridad eclesiástica. Y hay un dato que puede soslayarse: el miedo a ser encarcelado, deportado o incluso asesinado persistía, pues estaban re-

87 «Cesáreo Barroso Nieto, testimonio al autor», en José Luis AlfaYA, La diócesis de Madrid-Alcalá durante la guerra civil: 1936-1939, Tesis Doctoral, Universidad de Navarra, Pamplona, 1987, p. 245. Por ser recuerdos de cincuenta años antes, Barroso primero niega que se entrevistara con Lobo y luego afirma que éste les habló. Siendo coherentes con el relato, parece que Lobo habló con los demás sacerdotes, y éstos comentaron a Barroso lo que había pasado.

${ }^{88}$ Manuel DE Irujo, Un vasco en el Ministerio de Justicia. Memorias 2. La cuestión religiosa. Primera Parte, Buenos Aires, Editorial Vasca Ekin 1978, p. 32.

${ }^{89}$ Gaceta de la República, 12-VIII-1937, n. 224, pp. 590-591; cfr. José M. MARGENAT Peralta, «Manuel de Irujo: la política religiosa de los gobiernos de la República en la guerra civil (1936-1939)», Cuadernos de Historia Moderna y Contemporánea, 4, Madrid, Universidad Complutense de Madrid 1983, p. 185. 
cientes los casos de sus compañeros torturados hasta la muerte. Era impensable llevar sotana por la calle, resultaba peligroso ser reconocido como sacerdote y bastantes presbíteros llevaban meses escondidos en casas particulares o refugiados en embajadas. El sacerdote republicano Gallegos Rocafull reconocía que, aunque ya no había asesinatos indiscriminados, «el ambiente seguía siendo encarnizadamente hostil y hacía falta temple de mártires para intentar reanudar la vida pública religiosa sabiendo que, al hacerlo, se jugaban su vida y la de sus feligreses». ${ }^{90}$

Por otro lado, el Gobierno Negrín no deseaba restablecer el culto público. Los ministros temían una reacción hostil y violenta de los anticlericales, pues los anarquistas se habían opuesto a la apertura de iglesias. ${ }^{91}$ Además, el Gobierno sospechaba que algunos católicos aprovecharían las reuniones en las iglesias para conspirar contra la República y fortalecer a los quintacolumnistas. Por eso, el Gobierno sólo permitió a Irujo una política de pasos pequeños y controlados.

Irujo convocó a Lobo de nuevo en Valencia la primera quincena de agosto. Tras las entrevistas con el ministro y los agentes de propaganda, Leocadio fue nombrado Jefe de la Sección de Confesiones y Congregaciones religiosas. Al regresar a Madrid, celebró una misa el 15 de agosto en la parroquia de San Ginés, a la que invitó a numeroso público, nacional y extranjero. ${ }^{92} \mathrm{Al}$ acabar el acto, se proyectó una película a favor del respeto al culto. ${ }^{93}$

Situado en ese momento en un despacho oficial del ministerio de Justicia, Lobo planeó su estrategia en cuatro frentes: conseguir sacerdotes dispuestos a celebrar el culto privado; recabar información sobre bienes religiosos que pudiesen ser empleados para el culto; recibir apoyos de Roma; e impulsar la propaganda. Dijo por carta al ministro que esperaba que «de no torcerse el carro en un plazo de dos meses habrá cambiado por completo el panorama religioso de Madrid». ${ }^{4}$

Las cosas salieron peor de lo previsto. Intentó de nuevo «recabar la adhesión de los sacerdotes al Gobierno, de proporcionarles avales y de hacer la ficha de los mismos. No llegarían a quince los que prestaron su adhesión». ${ }^{95}$ Entre ellos, Cándido López Blázquez, ecónomo de Quijorna; Vidal Balmisa Moreno, colec-

90 José M. Gallegos Rocafull, La pequeña grey..., op. cit., p. 126.

${ }^{91}$ Cfr. Hilari Raguer, La Espada y la Cruz. La Iglesia, 1936-1939, Barcelona, Bruguera 1977, p. 205.

92 Cfr. Antonio Marquina Barrio, La diplomacia vaticana y la España de Franco (1936-1945), Madrid, CSIC 1983, p. 420.

${ }^{93}$ Cfr. New York Times, 16-VIII-1937.

${ }_{94}$ Leocadio Lobo a Manuel de Irujo, Madrid, 19-VIII-1937, en AMI, 21, 1, 31.

${ }_{95}$ Declaración de Albino Jiménez Fernández, Madrid, 16-VI-1939, en Expediente personal de Leocadio Lobo Canónigo, ACCAM, XV, A 13.

Hispania Sacra, LXII

125, enero-junio 2010, 267-309, ISSN: 0018-215-X 
tor de la parroquia de San Marcos; Serafín Sola; Anastasio Fernández; y Ángel Marco. ${ }^{96}$ La carta de solicitud para practicar el culto incluía unas líneas en las que se decía expresamente que los sacerdotes se abstendrían de hacer política. ${ }^{97}$

El nuevo fracaso demostraba lo lejos que estaba de sus compañeros. Éstos formaban el clero de la Iglesia clandestina en Madrid, dirigida entonces por Heriberto Prieto, vicario en Madrid del Obispo Eijo Garay, y por José María García Lahiguera. Los sacerdotes recibían dinero republicano, confiscado por las tropas de Franco, y colaboraban con el movimiento quintacolumnista. En la ciudad había más de cien lugares donde se celebraba misa.98

Leocadio Lobo no deseaba crear un cisma o una Iglesia paralela presidida por él. Buscaba dar cauce al deseo de tener culto y dirigirlo de acuerdo con su condición de jefe de la Sección de Confesiones y Congregaciones religiosas. Pero, indirectamente, ese cargo ponía bajo su mando político la Iglesia en Madrid sin una autorización de la Santa Sede ni de su Obispo.

Rota la comunicación con Eijo Garay, residente en Vigo, Lobo buscó apoyos del Vaticano. Primero intentó, sin éxito, que Max-Alfonso Ariz Elcarte, Canciller de la nunciatura, fuese a Roma con algún miembro del Gobierno para tratar «sobre la sistemación del culto religioso en España».99 Después, "In October 1937 several priest have met in Madrid under the presidency of the Canon Doctoral Juan Aguilar and we sent absolutely canonical petitions to Rome». ${ }^{100} \mathrm{La}$ noticia de su petición a la Santa Sede llegó al Cardenal Gomá a través de la superiora del Hospital de francés de Madrid. Según esta religiosa, Lobo había escrito a Roma «pour demander des «Normas» à suivre dans les circonstances actuelles et conformes au milieu rouge», ${ }^{101}$ incluyendo en la petición a tres sacerdotes a los que no había consultado: José María García Lahiguera, Emilio González y Juan Echevarría. ${ }^{102}$

${ }^{9}$ Cfr. Leocadio Lobo y otros sacerdotes a Manuel de Irujo, Madrid, 9-XI-1937, en AMI, 21, 1, 49.

97 Cfr. New York Times, 13-VIII-1937.

98 Cfr. José Luis Alfaya, Como un río de fuego..., op. cit., especialmente el apartado «Organización clandestina», pp. 155-180.

${ }_{99}$ Max-Alfonso Ariz Elcarte a Manuel de Irujo, Madrid, 19-IX-1937, reproducido en Manuel DE Irujo, Un vasco en el Ministerio de Justicia. Memorias 2. La cuestión religiosa. Segunda Parte, Buenos Aires, Editorial Vasca Ekin 1979, pp. 528-529.

${ }^{100}$ Leocadio Lobo a mons. Michael Ready, Los Angeles, 29-III-1939, en ACUA, National Catholic Welfare Conference, Box 16 Folder 8 (Lobo, Leocadio).

101 Isidro Gomá a Hildebrando Antoniutti, Pamplona, 17-X-1937, en Archivo Gomá: documentos de la guerra civil, Documento 8-114.

102 José María García Lahiguera había sido el director espiritual del seminario de Madrid; Emilio González y González había ocupado el cargo de profesor de Metafísica, también en el Seminario. El tercer nombre debe ser José Echeverría, párroco de San Antonio de Padua. Cfr. Expediente personal de José María García Lahiguera, ACCAM, V A 1.2.3; Expediente personal de Emilio González y González, ACCAM, XV, A g 11; Expediente personal de José Echeverría Bolumburu, ACCAM, XV, A e 1. 
Nada más conocer esta maniobra, el Cardenal Gomá escribió a Hildebrando Antoniutti, recién nombrado Encargado de Negocios de la Santa Sede en la España nacional, pidiéndole que el Secretario de Estado estuviese al tanto de «los manejos de ciertos sacerdotes poco menos que renegados, cuyas actividades aprovecha el bolchevismo de Valencia para sus fines de propaganda internacional y para desvirtuar la historia de destrucción y persecuciones que ha sufrido la Iglesia católica en las zonas ocupadas por los rojos».103 Pensaba Gomá que Lobo alistaría a muchos sacerdotes porque «el hambre y el miedo son malos consejeros». Por eso quería evitar que la Santa Sede aprobara algo no autorizado por el Obispo de Madrid-Alcalá. Zanjaba Gomá: «el conato de reinstauración del culto público en la zona roja deberá ser considerado como un hecho de cisma o indisciplina colectiva».

Antoniutti informó al cardenal Pacelli a favor de la tesis de Gomá. La maniobras de Lobo «hanno la parvenza di un movimento tendencialmente politico».104 Prevenía a la Santa Sede de modo que, antes de aceptar la propuesta, valorara las posibles implicaciones para no «indurre in errori diversi preti residenti nella Spagna rossa», y ver que «non sia il caso di far conoscere che si tratta semplicemente de mire politiche per ingannare l'oppinione internazionale».

Otra línea de trabajo de Leocadio Lobo fue la recogida de material útil para el culto religioso o para su dirección del Negociado de Confesiones y Congregaciones Religiosas. En el archivo de las Congregaciones religiosas, encontró «más de cuatro mil expedientes perfectamente organizados en un magnífico fichero y tres libros sobre las mismas». ${ }^{105}$ Investigó también en el obispado de Madrid. Allí leyó la documentación y correspondencia privada del Obispo Eijo Garay y se llevó algunos documentos delicados, como un fichero de sacerdotes, unos legajos titulados «Secretos de conciencia» y un pliego lleno de firmas de fieles de Madrid que pedían a Eijo que dejara votar a las monjas de clausura. No entregó esa documentación al vicario de Eijo Garay en Madrid; en cambio, leyó en ocasiones parte de esos documentos a otras personas en su despacho del ministerio, diciendo «que no los publicaba porque no tanto herirían a las personas cuanto a la Religión misma».106 El escritor Arturo Barea, que conoció a Leocadio Lobo durante esos meses, recreó sus recuerdos de aquel sacerdote que «tenía su propia batalla mental. Lo que le hería más hondo no era la furia

103 Isidro Gomá a Hildebrando Antoniutti, Pamplona, 17-X-1937, en Archivo Gomá: documentos de la guerra civil, Documento 8-114.

104 Hildebrando Antoniutti a Eugenio Pacelli, Bilbao, 18-X-1937, en Archivio Segreto Vaticano, Arch. Nunz. Madrid, 972, ff. 402-403.

105 Leocadio Lobo a Manuel de Irujo, Madrid, 19-VIII-1937, en AMI, 21, 1, 31.

106 Declaración de Albino Jiménez Fernández, Madrid, 16-VI-1939, en Expediente personal de Leocadio Lobo Canónigo, ACCAM, XV, A 13.

Hispania Sacra, LXII

125, enero-junio 2010, 267-309, ISSN: 0018-215-X 
desatada contra las iglesias y los curas por gentes brutales, enloquecidas y llenas de rencores, sino el conocimiento de la culpabilidad de su propia casta».107

Según la Secretaría Política de Manuel de Irujo, Leocadio Lobo también tuvo acceso a parte del archivo secreto del Cardenal Gomá. Al ocupar Toledo, los milicianos se apoderaron de esa documentación, en la que «existían unas memorias íntimas y notas reservadas que contenían ataques de fondo contra la política del Vaticano, por liberal, demócrata y social». ${ }^{108}$ Este material tan sensible podría ser útil para «las relaciones internacionales entre el poder civil y la Iglesia. Fueron hallados datos de gran intimidad bajo sobre lacrado, cuya cobertura indicaba no poder ser abierto hasta después de la muerte del Cardenal. Entre estas intimidades se encuentran graves acusaciones contra el Cardenal Segura». La documentación sirvió para acentuar la repulsa de Leocadio Lobo a las ideas políticas de Isidro Gomá.

Lobo colaboró asimismo con la Delegación de Propaganda. Mantuvo encuentros con la prensa, explicó en los periódicos las actividades encaminadas al restablecimiento del culto y repitió que los sacerdotes vivían pacíficamente, siendo respetados por todos. En un artículo publicado por el Servicio Español de Información, decía que eran centenares los curas «que han sido nombrados presidentes de comités de casas y aun de barriada; otros organizan secciones del Socorro Rojo (...). En Madrid son muchos los niños que se bautizan, los enfermos que reciben asistencia espiritual y los matrimonios según el rito de la Iglesia; conozco sacerdotes que, faltos de medios, reciben cada día el pan de manos de los trabajadores». ${ }^{109}$ En agosto, estas palabras aparecieron en la prensa internacional con el fin de mostrar la libertad de que gozaban los sacerdotes para ejercer el culto privado en la zona republicana, incluso en los frentes de guerra. ${ }^{110}$

Dato anecdótico pero clarificador de sus actividades fue el rodaje de una película, impulsada por Lobo para mostrar la nueva situación del clero y la apertura del culto. El sacerdote acompañó a las cámaras cuando acudieron a filmar un establecimiento penitenciario y una residencia de religiosas en Alcalá de Henares. ${ }^{111}$ También organizó, con ayuda de miembros de la CNT, una exposición de imágenes sagradas y de ornamentos en la iglesia del Carmen de Madrid. ${ }^{112}$

107 Arturo BAREA, The Clash, London, Faber and Faber 1946. Esta novela forma junto con The Forge (1941) y The Track (1943), una trilogía titulada The Forging of a Rebel, que apareció en castellano como La forja de un rebelde.

108 Manuel de Irujo[?] a Juan Oreaga, Barcelona, 26-X-1938, en AMI, 22, 2A, 59.

${ }^{109}$ Leocadio LoBO, «Cómo respetó el pueblo el tesoro artístico eclesiástico», El catolicismo en la España leal y en la zona facciosa, Madrid-Valencia, Servicio Español de Información 1937, pp. 8-11.

110 Cfr. The age, 14-VIII-1937; The Canberra Times, 14-VIII-1937.

111 Cfr. Leocadio Lobo a Manuel de Irujo, Madrid, 19-VIII-1937, en AMI, 21, 1, 31.

112 Cfr. $A B C, 22-\mathrm{XI}-1938$. 


\section{El intento de restablecer el culto público en España}

A finales de 1937, Leocadio Lobo se trasladó a Barcelona para colaborar más con el Gobierno, sobre todo con el ministro Irujo. Las dificultades encontradas en Madrid para abrir una iglesia pública se simplificaron. Según Leocadio, «desde diciembre de 1937 en que me trasladé a Barcelona celebré el Santo Sacrificio en una capilla pública, teniendo conocimiento de ello el Señor Vicario General de Barcelona, Padre Filipense», 113 que era el Padre José María Torrent.

Desde Barcelona, Leocadio escribió una larga carta al editor de The Times en junio de 1938 para refutar los argumentos publicados en ese periódico sobre la persecución religiosa en la zona republicana, especialmente en las cartas del jesuita británico George Burns. Las cifras eran, sin duda, aplastantes: proporcionalmente el clero había sido uno de los grupos sociales más perseguidos durante la Guerra Civil española, con más de 6.000 sacerdotes asesinados. Lobo había reflexionado largo tiempo sobre este tema, y ahora los afrontaba a fondo por primera vez. ${ }^{114}$

Antes de ser traducida al inglés, la carta fue cuidadosamente revisada. Pasó por las manos de Constancia de la Mora, jefe de la Oficina de prensa extranjera de la Subsecretaría de Propaganda, y por las del ministro de Estado, Julio Álvarez del Vayo. Después fue despachada a través de la embajada española en Londres. ${ }^{115}$

Lobo sostenía que los asesinatos de sacerdotes en España se cometieron por razones políticas, no porque hubiese una persecución religiosa: «Nearly every priest who has fallen in this horrible battle (...) has fallen as a politician». Miles de sacerdotes habían sido miembros de partidos políticos, habían predicado ideas políticas en las iglesias, habían permitido la venta de periódicos que atacaban al Gobierno y al pueblo a la entrada de las parroquias y habían guardado armas en las iglesias. Sin citar la documentación sustraída en el obispado de Madrid, afirmaba que muchos católicos solicitaron a las autoridades religiosas que las monjas de clausura saliesen a votar.

El Gobierno republicano no había alentado la persecución política contra el clero: "At the beginning of the rebellion, no doubt, feelings were uncontrolled, and ignorant or wicked people took personal advantage of that horrible opportunity. Yet nobody can seriously assert that the authorities issued order for per-

\footnotetext{
${ }^{113}$ Leocadio Lobo a mons. Michael Ready, New York, 4-III-1939, en ACUA, National Catholic Welfare Conference, Box 16 Folder 8 (Lobo, Leocadio).

${ }^{114}$ Leocadio LoBo, Open Letter to the Editor of the «Times», Barcelona, junio 1938, en London School of Economics Archives, Coll Misc 0091/38.

115 Cfr. Soledad Fox, Constancia de la Mora in War and Exile. International Voice for the Spanish republic, Portland (Oregon), Sussex Academic Press 2007, p. 76. 
secution, or that they ever prohibited freedom of worship». Por tanto, si no había ahora culto, era porque los Obispos, sacerdotes y fieles no querían: "Whose fault is it if religious worship in our territory is irregular? The confession is painful, but necessary. The fault is ours and only ours. We have not expressed a word of gratitude or a sign of appreciation for the good treatment we have received. Why? Simply because we do not wish to do it. It is convenient to go on and far more profitable for Franco's cause, and for that of the Spanish Bishops who still desire to keep in the background, to talk of catacombs and persecution, and to use the word "martyriology" .

Al utilizar el término «cruzada», los Obispos españoles habían transferido un conflicto de orden económico, social y político a la esfera religiosa. Este giro, que calificaba de «estúpido», y el hecho de que sostuvieran al general Franco, rebelado contra el poder constituido, hacía a la Iglesia española corresponsable de la catástrofe. "The military rebellion would never have reached such great importance or, perhaps started at all without the assistance of the Church. If there have been innocent victims, the military rebels, the phalangists, the Bishops, priests and monks are responsible».

Lamentó que la Iglesia española hubiese abandonado en ocasiones su deber de evangelizar, por causas sociales, contentándose con prácticas externas. Contrastaba esta actitud con la de la Santa Sede, propensa a escuchar las voces que llegaban de las dos zonas en guerra. "We shall have normal religious life as soon as we say to the Spanish Government and people: "As Ministers of the Catholic Faith we declare that we have nothing in common with politics. Our only desire is freedom of Religion and Worship" ".

A principios del segundo semestre de 1938, Leocadio Lobo regresó a Madrid. Ocupó un despacho en la Delegación general de Euzkadi. Su trabajo siguió unas pautas semejantes a las de meses atrás: organizar el culto católico, tratar de abrir al público alguna iglesia, mantener el contacto con la prensa y colaborar con la propaganda. En ese momento, ni la coyuntura militar ni la diplomática eran las más deseables para los republicanos. El Gobierno de Juan Negrín veía cercano el fin de una guerra dada por perdida. Tendría que afrontar una última y dura exigencia: la rendición incondicional. Por su parte, el Vaticano se alejaba cada vez más de la República, pues el 10 de junio Gaetano Cicognani había sido nombrado nuncio en la España nacional.

El 5 de noviembre, Miguel San Andrés, periodista y delegado de propaganda y prensa en Madrid, recibió una «Carta abierta» del sacerdote Seviliano Otin dirigida al «Sr. Don Leocadio Lobo y demás sacerdotes adictos al izquierdismo republicano». ${ }^{116}$ Otin criticaba el colaboracionismo con los radicales de iz-

116 Seviliano Otin a Miguel San Andrés, Madrid, 5-XI-1938, en Expediente personal de Leocadio Lobo Canónigo, ACCAM, XV, A 13 . El tono de la carta demuestra lo bien que conocía el autor a «mi 
quierdas. Señalaba que no contaban con autorización de la Jerarquía. Los párrafos centrales de la carta son una sugerente réplica a las ideas de Lobo sobre el pueblo y la persecución. Otin diferencia el genérico «pueblo», al que «pertenecemos todos» de los obreros que «trabajan para un amo o patrono, mediante un jornal o retribución». Afeaba a los políticos, tanto de derechas como de izquierdas, por no haber auxiliado al obrero, motivando así la guerra. «Pero no os corresponde la exclusiva de defender ni amar al obrero entre los sacerdotes porque miles pueden contarse que han consagrado sus afanes a la cuestión social... y bien pocos los que han logrado llevar a cabo sus proyectos, porque no les ayudaron las derechas o más principalmente porque se opusieron las izquierdas». ${ }^{117}$

Otin censuraba la actitud de Lobo, negadora de la persecución religiosa bajo la excusa de que se trataba de una persecución política: «Digno era y es de justicia el obrero, y de que los defendamos de todas las maneras que nos sea posible los Sacerdotes después de la guerra, pero en la guerra ¡No! ¿No sabes que el obrero fue y es instrumento vivo... aunque inconsciente de ideales que son enemigos de Cristo y de su Iglesia? ¿Y que ha destruido templos y que ha asesinado a miles de Sacerdotes? ¿Y que los templos no destruidos están todos profanados? Verdad es que los que los han envenenado y empujado a tanto crimen son más culpables, pero ¿no han sido y son todos verdaderos perseguidores de la Religión y de la Iglesia? ¡Pero vosotros habéis dicho que no hay tal persecución!».

Con el fin de evitar más escisiones entre los católicos y de ganar prestigio internacional, el Gobierno aceleró el proceso de restablecimiento del culto público. ${ }^{118}$ En Madrid, Lobo empezó a celebrar la misa: «el primero de noviembre de 1938 abrí en Madrid la capilla del Santísimo Cristo de la Paz a la cual asistieron muchos católicos y de la cual tenía conocimiento el Dr. Heriberto Prieto, Vicario General de la diócesis». ${ }^{119}$

El 9 de diciembre, el Gobierno aprobó por decreto el Comisariado de Cultos para garantizar su libre ejercicio. La medida no pasó de una declaración de deseos, pues el mes siguiente las tropas de Franco entraban en Tarragona y Barcelona, acabando de hecho la Guerra Civil. No obstante, interesa ver que la noticia del restablecimiento del culto vino acompañada en varios periódicos por una entrevista que un redactor del Heraldo de Madrid hizo a Leocadio Lobo. El periodista comenzó su artículo diciendo que había visitado el domicilio del pa-

\footnotetext{
antes amigo Lobo». Todo apunta a que el nombre es un pseudónimo que esconde a uno de los sacerdotes clandestinos de Madrid.

${ }^{117}$ Las cursivas están en mayúsculas en el original.

118 Cfr. Antonio Montero Moreno, Historia de la persecución religiosa en España: 1936-1939, Madrid, BAC 1999, p. 80.

119 Leocadio Lobo a mons. Michael Ready, New York, 4-III-1939, en ACUA, National Catholic Welfare Conference, Box 16 Folder 8 (Lobo, Leocadio).
}

Hispania Sacra, LXII

125, enero-junio 2010, 267-309, ISSN: 0018-215-X 
dre Lobo en la calle de Tamayo, donde había acondicionado un oratorio en el que celebraba misa todos los domingos. Durante la espera, pudo admirar dos retratos dedicados, uno del general Miaja y otro del coronel Casado. Al llegar, Lobo dijo al reportero: «se está preparando la apertura de tres templos. Uno de ellos, San Antonio de los Alemanes, y dos más. Esto, por ahora». ${ }^{120}$ Lobo criticó a «la mayoría de los católicos, que no quiere decir buenos cristianos, interesados en aumentar desproporcionadamente las persecuciones de que dicen se les hace objeto, a fin de convertir el sentimiento católico en un arma política».

$\mathrm{Al}$ día siguiente, a las once y media de la noche, Leocadio habló a través del micrófono de La Voz de España Republicana para condenar, como ya lo había hecho el Papa, la persecución de los judíos en Alemania. Se refirió luego a la situación española: «yo no soy judaizante, como no soy comunista ni cura renegado». ${ }^{121} \mathrm{Se}$ avergonzaba de la matanza entre hermanos. Abogó por la retirada de las tropas extranjeras, pues en septiembre había comenzado la retirada de las Brigadas Internacionales. Pidió «que nos dejen solos, que, hermanos al fin, podremos y querremos entendernos». Reiteró las causas remotas de la guerra: «si para muchos la raíz del mal está en lo ocurrido desde Febrero hasta Julio de 1936, yo me permito remontarme un poco más alto y pensar en los días más lejanos, en dos siglos por lo menos de desviaciones y de miserias para nuestra patria».

El 16 de diciembre, pronunció una conferencia, titulada «La liturgia cristiana y el arte», en el salón de la Alianza de Intelectuales Antifascistas de Madrid, transmitida por Unión Radio. Amante de la liturgia desde hacía años, Lobo no tuvo dificultades para disertar durante una hora sobre «la evolución y significado del ritual cristiano»,, 22 mientras ilustraba sus explicaciones con muestras de música religiosa. Al concluir rogó «a los oyentes que no aplaudiesen su disertación "pues ante la grave prueba que ha atravesado la Iglesia católica en España, por culpas que no es necesario declarar, me basta con la satisfacción de haber puesto todo mi esfuerzo a su servicio y al de España"».

Tuvo una conversación con el vicario Heriberto Prieto el día 23 de diciembre: «hablé largamente con dicho Señor Vicario General y obtuve la debida autorización para abrir al culto la Iglesia madrileña de San Antonio de los Portugueses, una de las muchas respetadas por el pueblo. En esta visita fui comisionado por el mismo Vicario General para abrir la capilla del Hospital Militar No. 6, calle del Cisne No. 12 y celebrar allí la Santa Misa el día de Navidad. Lo realicé, predicando el Santo Evangelio y administrando los Sacra-

\footnotetext{
${ }^{120}$ Heraldo de Madrid, 9-XII-1938. El artículo fue reproducido en ABC, 10-XII-1938.

${ }^{121}$ La Libertad, 11-XII-1938; ABC, 11-XII-1938.

122 ABC, 17-XII-1938.
} 
mentos de la Confesión y la Comunión a varios soldados». ${ }^{123}$ La Delegación de Propaganda envió estas noticias a la prensa nacional y extranjera. ${ }^{124}$

\section{EL EXILIO EN EstADOS UNIDOS (1939-1959)}

Durante la Guerra Civil, el Medical Bureau and North American Committee to Aid Spanish Democracy (NAC) fue uno de los principales organismos norteamericanos que recogió fondos para la República española. ${ }^{125}$ El NAC subvencionó varias giras de conferenciantes por Estados Unidos, en las que participaron entre otros José Bergamín, el sacerdote Michael O'Flanagan, antiguo directivo del Sinn Fein y muy crítico con el Papa y los Obispos. ${ }^{126}$ Por su parte, algunos católicos americanos influyentes trabajaron a favor de los nacionales, como la America Spanish Relief Found, que conseguía fondos y los enviaba para que fuesen distribuidos por el Cardenal Gomá. Esta institución estaba dirigida por el jesuita Francis Talbot, editor de la revista America. ${ }^{127}$

Invitado y subvencionado por el NAC para hablar en Estados Unidos, Leocadio Lobo dejó Madrid el 29 de enero de 1939. No era ingenuo: dejaba España en un momento dramático, la guerra estaba prácticamente acabada y Franco era el vencedor. Quizá vio esta oportunidad como un modo de dar un salto adelante, de seguir apoyando la causa republicana en el extranjero, esperando el regreso de la República a España. Estuvo antes en Francia, donde se entrevistó con el Cardenal Verdier, Arzobispo de París, y con un grupo de españoles, entre los que se encontraba José Bergamín. El 27 de febrero su barco atracaba en el puerto de Nueva York.

Su llegada no pasó inadvertida ni a las autoridades eclesiásticas ni a la prensa. La National Catholic Welfare Conference (NCWC) -la Conferencia de Obispos de Estados Unidos- sabía que el Partido Comunista colaboraba con las actividades de los republicanos españoles exiliados en Estados Unidos. Según sus informaciones, el NAC «has been repeatedly charged with being Cотmu-

${ }^{123}$ Leocadio Lobo a mons. Michael Ready, New York, 4-III-1939, en ACUA, National Catholic Welfare Conference, Box 16 Folder 8 (Lobo, Leocadio).

${ }^{124}$ Cfr. New York Times, 2-I-1939.

125 Cfr. Columbia University Archives, Spanish Refugee Relief Organization Records (en adelante SRRO), Part B, Box 9, «Delegation from Spain».

${ }^{126}$ La gira de conferencias fue resumida por José M. SÁNCHEZ, «Priests and Suspect Catholics: Visitors from Loyalist Spain to America», The Catholic Historical Review, LXXVIII/2 (1992) 207-216.

127 Cfr. Special Collections Research Center (en adelante SCRC), America Magazine Archives, Box 38, Folder 14 (America Spanish Relief Found - Organization). America Spanish Relief Found vivió tres años, de 1937 a 1940. Durante este periodo envió al Cardenal Gomá algo menos de 100.000 dólares. 
nist controlled, have the Communist Party and the Young Communist League as two of its principal affiliates».128

Mons. Michael J. Ready, secretario general de la NCWC, había sido advertido meses antes por el Cardenal Gomá de la suspensión a divinis de Leocadio Lobo. El mismo 27 de febrero estableció cuál era la postura oficial: el sacerdote era un propagandista de izquierdas que había firmado diversos manifiestos distribuidos por los comunistas en todo el mundo, defendía la causa de quienes habían asesinado a diez mil sacerdotes, y pesaba sobre él una pena canónica. ${ }^{129}$

A los pocos días, la NCWC envió una carta circular a todos los directores diocesanos de Estados Unidos explicando estas ideas. Subrayaba que el sacerdote español había sido entrevistado por la prensa americana pro-Loyalist durante la Guerra Civil española, y que «many well meaning persons who do not realize the Communistic background of this organization [Medical Bureau] are supporting it in the belief that they are doing a humanitarian work». ${ }^{130}$

También la prensa cubrió las andanzas de Leocadio Lobo. Nada más desembarcar, Lobo afirmó que contaba con el pleno apoyo del Vicario general de Madrid, Heriberto Prieto, y que su viaje tenía como finalidad la búsqueda de «bread and understanding». ${ }^{131}$ En nombre del pueblo de España, quería explicar por qué la Guerra Civil no era una guerra de religión y conseguir fondos con los que alimentar a la población. Nada justificaba el asesinato de sacerdotes, pero, al menos podía explicarse debido a que muchos habían defendido intereses mundanos y habían estado afiliados a partidos políticos. Dijo estar en posesión de un documento dirigido por varios aristócratas madrileños a mons. Eijo Garay solicitándole su venia para que las monjas de clausura pudieran acudir a votar en las elecciones de 1933.

El 2 de marzo, Lobo pronunció una conferencia en el Hotel Center, de Nueva York. No hablaba inglés, por lo que contó con un intérprete. Acudieron más de mil ochocientos delegados de la American Federation of Labor y del Congress of Industrial Organizations. Estas organizaciones obreras pensaban que la Guerra española surgió «to resist fascist aggression against the democratic na-

128 Paul R. Martin-Dillon, Director of the Bureau of Information, Circular Letter to All Diocesan Directors of Information, Washington, 2-III-1939, en ACUA, National Catholic Welfare Conference, Box 16 Folder 8 (Lobo, Leocadio).

${ }^{129}$ Cfr. Michael J. READY, Statement, Washington, 27-II-1939, en ACUA, National Catholic Welfare Conference, Box 16 Folder 8 (Lobo, Leocadio). La cifra final de curas asesinados durante la Guerra Civil fue algo superior a los seis mil, y no diez mil.

130 Paul R. MARTin-Dillon, Director of the Bureau of Information, Circular Letter to All Diocesan Directors of Information, Washington, 2-III-1939, en ACUA, National Catholic Welfare Conference, Box 16 Folder 8 (Lobo, Leocadio).

131 Daily Worker, 1-III-1939. El periódico estaba subvencionado por el Partido Comunista de los Estados Unidos. 
tions of the World». ${ }^{132} \mathrm{El} 8$ de marzo tuvo otro acto en Flushing, Nueva York. Intervino también un teniente coronel americano que había luchado en las Brigadas Internacionales. ${ }^{133}$

Cuando llegó a oídos de Lobo que mons. Ready mencionado su suspensión canónica, le escribió para decirle que durante la guerra había estado en contacto con la nunciatura de Madrid y que no tenía noticia alguna de tal pena; por tanto, concluía Leocadio, debían presentar pruebas. ${ }^{134}$ Mons. Ready pidió al Cardenal Gomá una confirmación por telegrama. Nada más recibirla, escribió a Lobo asegurándole que estaba suspendido y exigiéndole que cesara de hablar en público: "All our citizens know that the agency sponsoring your lectures in our country is communistic in character and direction. By co-operating in the vicious propaganda of the known enemies of the Catholic Church in the United States you have become thereby a source of grave scandal to the Catholic and other Christian people of this country». 135

Pero, cumpliendo los planes del NAC, Leocadio Lobo había comenzado ya una agotadora gira de veintitrés conferencias sobre la República española y la Guerra Civil. Viajando en tren o autobús, recorrió las principales ciudades norteamericanas entre el 10 de marzo y el 28 de abril. ${ }^{136}$ En algunas se encontró con quinientas personas y otras veces sólo con unas pocas decenas. Siempre habló con intérprete y apareció en público vistiendo traje clerical. Cuando hizo una colecta, recaudó más bien poco, destinando ese dinero a los niños de la zona republicana a través del NAC. Expuso con libertad sus ideas, pero no pudo evitar que la prensa católica lo presentara como un sacerdote suspendido, ${ }^{137}$ algo que la NCWC repetía con frecuencia en sus declaraciones oficiales de esos meses..$^{138}$

132 Daily Worker, 2-III-1939.

${ }^{133} \mathrm{El}$ panfleto que anunciaba el acto puede verse en Archdiocesan Archives, Archdiocese of New York (en adelante AANY), CH-2-P, «Lobo, Rev. Leocadio».

134 Cfr. Leocadio Lobo a mons. Michael Ready, New York, 4-III-1939, en ACUA, National Catholic Welfare Conference, Box 16 Folder 8 (Lobo, Leocadio). Lobo envió esta misma carta a diversos medios de comunicación, y éstos se apresuraron para publicarla: La Prensa, 7-III-1939. El borrador de la carta, en SRRO, Part O, Box 2, «Organization - Lobo (Father Leocadio)».

135 Mons. Michael Ready a Leocadio Lobo, Washington, 9-III-1939, en ACUA, National Catholic Welfare Conference, Box 16 Folder 8 (Lobo, Leocadio). Ese mismo día, Ready escribía a todos los Obispos americanos para advertirles de los viajes que iba a realizar Lobo.

136 El calendario y algunos anuncios de estos encuentros pueden verse en SRRO, Part N, Box 1, «Tour- Father Lobo- Corrsp.». El itinerario fue pronto conocido por la NCWC: cfr. Circular Letter to All Diocesan Directors of Information, Washington, 10-III-1939, en ACUA, National Catholic Welfare Conference, Box 16 Folder 8 (Lobo, Leocadio).

137 Cfr. The Michigan Daily, 11-III-1939.

138 Cfr. Two Speakers Withdraw as Suspended Priest is Heard at Meeting, N.C.W.C. News Service, Washington, 20-III-1939, en ACUA, National Catholic Welfare Conference, Box 16 Folder 8 (Lobo, Leocadio). 
En unas pocas ciudades, los católicos consiguieron evitar que Leocadio pronunciara la conferencia prevista. ${ }^{139}$

Lobo incidió en dos temas: las características del Gobierno de Franco y las razones de la persecución anticlerical en España. Calificó al régimen franquista como un sistema fascista que anulaba la vida cristiana. Durante una intervención, Lobo recordó la respuesta de un trabajador cuando el sacerdote quiso descolgar el cuadro de un Crucificado en la iglesia de las Maravillas de Madrid: «No, Father Lobo, no -we are Catholics- but even if we were not - you would not take that picture away. Christ is our brother and our friend. The fascists of his day killed him, just as they would do today if He returned to preach».140

Sobre la causa de la persecución, señaló que el clero español había abandonado su deber evangelizador de los más pobres. Éstos, azuzados por la propaganda y por el hambre, habían acudido a la revolución. "The people practiced the Christian rites in the solemn moments of their lives. (...) And yet they were lacking in religious instruction; nor did they live, I believe in many cases on account of ignorance, according to Christian dogma. And we priests took refuge among the wealthy classes, perhaps deserting our duty. The Spanish clergy is honest and fervent, but it was not prepared for the struggle which inevitably had to come».

Durante la Guerra Civil, Lobo había negado repetidas veces que estuviese suspendido, alegando que nada le habían dicho los representantes de la Santa Sede o el vicario del Obispo Eijo Garay en Madrid, Heriberto Prieto. Ahora, en cambio, la confirmación rotunda de mons. Ready no dejaba lugar a dudas. El 24 de marzo, en su conferencia de Louisville, Kentucky, Leocadio Lobo reconoció públicamente su situación, y expresó el gran dolor que le producía: «I am not an apostate priest. The greatest sacrifice of my life is that I am unable to celebrate the Mass at this time». ${ }^{141}$

Cinco días más tarde, Lobo escribió una larga carta a mons. Ready. Reiteró su adhesión a la fe y a la Jerarquía, insistió en su profunda tristeza por la noticia de la suspensión y negó ser un representante oficial u oficioso de los comunis-

139 Cfr. Charles J. Ducey a Francis X. Talbot, New Haven, Conn., 27-IV-1939, en SCRC, America Magazine Archives, Box 38, Folder 20 (America Spanish Relief Found - Leocadio Lobo). Ducey trabajaba en el Service Department of Knights of Columbus en New Haven, Connecticut. La situación canónica de Lobo apareció publicada en America. A Catholic review of the week, 13-V-1939, p. 99.

140 «Father Lobo: Priest of Madrid. The vicar of San Giñes[sic] comes to America to plead for his people. A priest faithful to the Spanish republic. The religious question explained», 9-III-1939, en SCRC, America Magazine Archives, Box 38, Folder 20 (America Spanish Relief Found - Leocadio Lobo).

141 «Resume of Father Lobo's Speech at Louisville, Kentucky», en Mons. Michael Ready a Cardenal Gomá, Washington 24-III-1939, ACUA, National Catholic Welfare Conference, Box 16 Folder 8 (Lobo, Leocadio). 
tas. Adujo que su postura política antifranquista era mantenida por otros eclesiásticos como el Cardenal Vidal y Barraquer o los Obispos de Vitoria, Orihuela o Salamanca, además de escritores católicos como Jacques Maritain o Georges Bernanos. En cambio, continuaba Lobo, ayudaban a Franco «the Moors, and Hitler and Mussolini».142 Finalmente, no renunciaba a seguir hablando porque su voz se alzaba en contra del fascismo: «Do not forget, Monseigneur, that I am a Spaniard and that while international fascism continues to spill torrents of Spanish blood and devastating Spain, no human force can impose silence upon me». Ready acusó recibo de su carta, e invitó a Lobo a hablar con él personalmente. No consta que ese encuentro se produjera. ${ }^{143}$

$\mathrm{Al}$ acabar su gira, Lobo se instaló en Nueva York. Allí intervino en encuentros a favor de la República española de forma intermitente. El 14 de mayo habló en un festival artístico a favor de los niños refugiados en campos de concentración franceses, que organizó el Comité Pro Democracia Española; y el 22 de mayo fue uno de los oradores del «grandioso mitin de afirmación antifascista y pro refugiados» celebrado en Madison Square Garden, y auspiciado por el Medical Bureau, el NAC y las Sociedades Hispanas Confederadas. ${ }^{144}$ En aquella ocasión, intervinieron también Juan Negrín, el ex ministro Julio Álvarez del Vayo, el literato Herman F. Reissing y Daniel Alonso, secretario de las Sociedades Hispanas Confederadas. El encuentro perseguía este doble propósito: «Resultados tangibles en el orden económico para los refugiados españoles, y la demostración palmaria a los fascistas españoles de New York de que nuestra Colonia es antifascista y odia y desprecia por igual a los traidores que ensangrentaron y entregaron la Patria a gente extraña».145

Durante la primavera, y sobre todo después de recibir la noticia del final de la Guerra Civil, Lobo le dio vueltas a sus posibilidades futuras, entre las que incluía viajar a Cuba o a México. ${ }^{146}$ Incluso recibió una invitación para dirigir el diario neoyorquino $\mathrm{La} \mathrm{Voz.}{ }^{147}$ Pasado el verano, Lobo se encontraba ante una grave y compleja situación: un sacerdote católico suspendido que no podía re-

\footnotetext{
142 Leocadio Lobo a mons. Michael Ready, Los Angeles, 29-III-1939, en ACUA, National Catholic Welfare Conference, Box 16 Folder 8 (Lobo, Leocadio).

143 Gomá agradeció a Ready sus noticias sobre «este desgraciado sacerdote». Confiaba en que, una vez conocida la suspensión, Lobo fuera propenso a «abandonar peligrosas compañías y se someta a las normas de sus Superiores»: Isidro Gomá a Michael Ready, Toledo, 2-V-1939, en ACUA, National Catholic Welfare Conference, Box 16 Folder 8 (Lobo, Leocadio).

${ }^{144}$ Cfr. Daily Worker, 24-V-1939.

145 Frente Popular. Órgano del Comité Antifascista Español de los Estados Unidos de Norte América, 12-V-1939.

${ }^{146}$ Cfr. Nota de Harry Robinson a Evelyn Ahrend, (sin ciudad), 23-IV-1939, en SRRO, Part N, Box 1, «Tour- Father Lobo- Corrsp.». Robinson era el traductor que acompañaba a Lobo y Ahrend era el director del Program Bureau, del NAC.

${ }^{147}$ Cfr. La Voz, 24-V-1939.
} 
gresar a su país, pues corría el riesgo de ser fusilado, ${ }^{148}$ y que no tenía familia cercana. A estos inconvenientes se sumaban la dificultad del idioma y de la idiosincrasia de Estados Unidos, además de la necesidad de asegurar los ingresos suficientes para vivir.

En su haber, estaban los amigos republicanos, los de la colonia española y los norteamericanos. Con ellos iba a relacionarse y, gracias a su influencia, pudo establecer los lazos necesarios para asentarse en Nueva York. Las Sociedades Hispanas Confederadas eran una «amalgama de muchas sociedades de emigrados y exiliados españoles, como la Casa de Galicia, el Ateneo Español y el Centro Asturiano, articulada para encauzar las actividades de sus diversas sociedades». ${ }^{149} \mathrm{~A}$ través de estas Sociedades, Leocadio Lobo hizo amigos como el poeta Bernardo Clariana o el literato Francisco García Lorca, con los que se reunía para charlar, compartiendo noticias y añoranzas, en algún bar de Greenwich Village, zona neoyorquina en la que residió durante ese tiempo. A la vez, mantuvo su apoyo a la República en el exilio, apareciendo en público junto a personajes como Alfonso Daniel Rodríguez Castelao o Basilio Álvarez. ${ }^{150}$

Tuvo que buscarse una ocupación. Consiguió un puesto de trabajo en la productora Metro Goldwyn Mayer, de la que llegaría a ser el Spanish Editor para las películas en versiones subtituladas y dobladas. ${ }^{151}$ También dio clases de castellano para los empleados de la Loew's International Corporation. ${ }^{152}$ Manuel Fernández-Montesinos, sobrino del poeta García Lorca, recuerda que acudió en 1942 a una representación de El Alcalde de Zalamea en un teatro de Nueva York. Allí «hacía el papel del protagonista Leocadio Lobo, el padre Lobo, como le llamaba todo el mundo». .53

El primer lustro de los años cuarenta fue una etapa de asentamiento en Nueva York. Pero, en su interior, Leocadio ansiaba volver a trabajar como cura. Los testigos de su vida en estos años son unánimes cuando explican que, aunque ya no llevaba traje sacerdotal, siempre se presentó como un sacerdote: ni renunció a su juramento de celibato ni contestó a la sanción canónica que tenía impuesta.

${ }^{148}$ Cfr. Leocadio Lobo a mons. Michael Ready, Los Angeles, 29-III-1939, en ACUA, National Catholic Welfare Conference, Box 16 Folder 8 (Lobo, Leocadio).

149 Manuel FernándeZ-Montesinos García, Lo que en nosotros vive, Barcelona, Tusquets 2008, p. 51.

${ }^{150}$ Cfr. Basilio Álvarez (ed. José Antonio Durán), España en Crisol, A Coruña, Ediciós do Castro 1989, p. 171.

${ }^{151}$ Como dato anecdótico, Leocadio Lobo dobló en castellano al pescador Manuel (Spencer Tracy) en la película Captains Courageous (Capitanes intrépidos).

${ }_{152}$ Cfr. Boxoffice, 12-IV-1947.

${ }^{153}$ Manuel Fernández-Montesinos García, Lo que en nosotros vive, op. cit., p. 51. 


\section{Un capellán de Manhattan}

Al menos desde 1946, Leocadio Lobo y el obispado de Madrid mantuvieron contactos oficiosos a través de católicos españoles que viajaban a Nueva York, como el pedagogo Víctor García Hoz o Estanislao Martín. Mediante estas personas, manifestó al Obispo Eijo Garay que deseaba ejercer de nuevo como sacerdote. En el diciembre pasó por Nueva York el Obispo de Ciudad Rodrigo, Máximo Yurramendi. Lobo y Yurramendi se entrevistaron con Edward Gaffney, Canciller de la diócesis de Nueva York, para «suplicar me permitiesen decir la Sta. Misa. Es demasiado duro para mí continuar en esta situación por más tiempo». ${ }^{154}$ Se inició entonces un proceso de rehabilitación que duró un año. Intervinieron autoridades eclesiales y gubernamentales, de España y Estados Unidos, pues el permiso de residencia de Lobo como «lay man» ${ }^{155}$ acababa en 1947.

En Madrid, su amigo en los años treinta, ya Obispo auxiliar, Casimiro Morcillo, le dijo por carta en febrero de 1947 cuáles eran las condiciones que imponía el Obispo Eijo Garay antes de levantar su suspensión: retractarse de sus declaraciones durante la Guerra Civil, restituir el dinero que había cogido en la parroquia de San Ginés y devolver los documentos sustraídos en el obispado. ${ }^{156}$

La respuesta no se conserva, pero debió ser fue intempestiva, al menos si se tiene en cuenta la correspondencia posterior. Morcillo en su siguiente carta puntualizó qué se le pedía:«Malversación de fondos. No he dicho que los malversara, sino que dispuso V. de fondos de la parroquia de San Ginés. (...) Sustracción de documentos. Asegura V. in verbo sacerdotis que no tiene ni uno solo. Está bien: aquí todavía creemos en la palabra de honor de los hombres. Pero no asegura V. que no se llevara ninguno. (...) Escándalo de los fieles. Que lo hubo no se le oculta a V. Nuestros fieles no comprenden todavía que un sacerdote pueda escribir en periódicos que atacan a la Iglesia, ni que pueda vociferar en un mitin y en la Radio sosteniendo la misma causa de los enemigos de la Religión». ${ }^{157}$ Morcillo trató de llevarlo hacia su terreno, con un tono algo irónico hacia las libertades americanas que Lobo aducía frente a la dictadura franquista: «no me parece digno de un hombre libre como V., residente en un país libre como Estados Unidos firmar una retractación «como quiera que sea»,

${ }^{154}$ Leocadio Lobo a Casimiro Morcillo, New York, 15-I-1947, en Expediente personal de Leocadio Lobo Canónigo, ACCAM, XV, A 13.

155 Amleto Giovanni Cicognani a Edward R. Gaffney, Washington 1-III-1947, en AANY, CH-2-P, «Lobo, Rev. Leocadio». Amleto Cicognani era delegado apostólico de la Santa Sede en Estados Unidos.

${ }^{156}$ Cfr. Casimiro Morcillo a Leocadio Lobo, Madrid, 14-II-1947, en Expediente personal de Leocadio Lobo Canónigo, ACCAM, XV, A 13.

157 Casimiro Morcillo a Leocadio Lobo, Madrid, 30-VII-1947, en Expediente personal de Leocadio Lobo Canónigo, ACCAM, XV, A 13.

Hispania Sacra, LXII

125, enero-junio 2010, 267-309, ISSN: 0018-215-X 
hecha por nosotros. Aun bajo la tiranía, los españoles saben siempre proceder con altivez que no es otra cosa que rectitud de conciencia. (...) Haga V. lo que debe y no sea niño, le digo yo con su misma frase. (...) Le vuelvo a asegurar que el Sr. Patriarca [Eijo] está deseando rehabilitarlo».

Leocadio no se lo pensó más. No se conserva su respuesta, pero, según el Obispo Eijo, «el 12 de agosto contestó pidiendo perdón y demandando su rehabilitación», ${ }^{158}$ asegurando que ni poseía ni tenía acceso a ningún documento o dinero sustraídos durante la Guerra Civil. El 8 de septiembre, Eijo Garay firmó el levantamiento de la pena de suspensión y le envió una carta de recomendación para el Arzobispo de Nueva York.

La pesadilla había llegado a su fin. Leocadio Lobo hizo Ejercicios espirituales en el convento de los capuchinos de Nueva York en noviembre. Al acabarlos, llamó por teléfono a Morcillo «y en términos expresivos y emocionados pidió perdón y manifestó que se sentía feliz por haber hecho Ejercicios y haber obtenido la remisión de sus penas canónicas y por sentirse perdonado por su Obispo». El Arzobispo de Nueva York le permitió celebrar misa en su archidiócesis. ${ }^{159}$ Lo hizo públicamente el 2 de diciembre en la iglesia de la Milagrosa, templo en el que había misas en castellano. A la celebración «asistió la mayoría de los miembros de la colonia española en esta ciudad, ante quienes el sacerdote expresó su satisfacción y alegría por haber vuelto a su sagrado ministerio. El padre Lobo declaró que había ofrecido la misa por el eterno descanso de los que murieron en la guerra civil española y que desde este momento se ofrece a todos los españoles como hermano para cuanto signifique ayuda espiritual». 160

Una vez rehabilitado, la actividad de Lobo se multiplicó, volviendo a ser el sacerdote incansable de las parroquias madrileñas de los años veinte y treinta. Su pastoral se desarrolló mayoritariamente en castellano, sobre todo con la comunidad puertorriqueña de Nueva York, en aumento desde la conclusión de la Segunda Guerra Mundial.

Lobo comenzó predicando Ejercicios y retiros espirituales en castellano en la iglesia del Cenacle. Y, al menos desde 1951, trabajó para las Catholic Charities de la archidiócesis, atendiendo a delincuentes de habla castellana en la oficina del abogado del Distrito de Manhattan. Además, durante los veranos ayudó

158 Leopoldo Eijo Garay a Cayetano Cigognani, Madrid, 27-XI-1947, en Expediente personal de Leocadio Lobo Canónigo, ACCAM, XV, A 1 3. Cayetano Cigognani era el nuncio de la Santa Sede en España.

159 Cfr. Edward R. Gaffney a Leopoldo Eijo Garay, New York, 11-XII-1947, en AANY, CH-2-P, «Lobo, Rev. Leocadio».

${ }^{160}$ La Vanguardia Española, 3-XII-1947. 
en el servicio sacerdotal de los campamentos de niños del CYO, de las Catholic Charities. ${ }^{161}$

Sus actividades sacerdotales no disminuyeron el trato que mantenía con los republicanos españoles en el exilio. En junio de 1949 el New York Times se hacía eco de la muerte de Fernando de los Ríos en su domicilio de Nueva York, e informaba que había acudido Leocadio Lobo a la capilla ardiente pues, aunque no hubo funeral o servicio religioso, el sacerdote era amigo de la familia. ${ }^{162} \mathrm{En}$ 1952 Lobo administró la Extremaunción y ofició el funeral católico por la madre de Fernando de los Ríos, Fernanda Urruti. ${ }^{163}$

Leocadio Lobo procuró asentar su posición eclesial. En enero de 1952 consiguió su primer nombramiento oficial en la archidiócesis de Nueva York: capellán del Carroll Club, una institución católica dedicada a formar profesional y cristianamente a mujeres obreras. Con la ventaja añadida de que el Carroll Club disponía de una residencia para el capellán, puso todo su empeño en la celebración de la misa y en las clases de español a las asociadas. Las mujeres que allí acudían, según un informe llegado al arzobispado neoyorquino, estaban agradecidas porque la «relationship with our membership is one of such mutual sympathy and understanding»,164 y por el discreto pero intenso trabajo sacerdotal de Lobo, que hizo de la capilla «a real center of devotion». En definitiva, era -según los informes de este momento- «sincerely religious and a true priest in every sense». .65

Además de atender el Carroll Club, Leocadio siguió colaborando con la oficina del abogado del Distrito de Manhattan. Empezó a celebrar la misa dominical, junto con algunos bautizos y bodas, en la parroquia de Sacred Hearts of Jesus and Mary. ${ }^{166} \mathrm{Y}$ un par de veces al mes, Lobo se encontraba con diplomáticos de Argentina y de Perú que trabajaban en Naciones Unidas. ${ }^{167}$

${ }^{161}$ Cfr. Harold S. Engel a mons. Lynch, New York, 21-I-1952, en AANY, CH-2-P, «Lobo, Rev. Leocadio».

162 Cfr. New York Times, 3-VI-1949; Manuel FernándeZ-Montesinos García, Lo que en nosotros vive, op. cit., p. 133.

${ }_{163}$ Cfr. Laura de los Ríos a Ritama y Fernanda Troyano, New York, 5-V-1953, en Ritama MuÑozROJAs, «Poco a poco os hablaré de todo». Historia del exilio en Nueva York de la familia de los Ríos, Giner, Urruti. Cartas 1936-1953, Madrid, Publicaciones de la Residencia de Estudiantes 2009, p. 451.

${ }^{164}$ Euphemia V. Rensselaer Wyatt a Harold S. Engel, New York, 23-I-1952, en AANY, CH-2-P, «Lobo, Rev. Leocadio».

165 Fr. Engel a mons. Lynch, New York, 21-I-1952, en AANY, CH-2-P, «Lobo, Rev. Leocadio».

${ }^{166}$ El primer registro de Lobo en esta iglesia es una boda que ofició el 22 de noviembre de 1952 a una pareja colombiana residente en Nueva York: cfr. Archives of the Church of The Sacred Hearts of Jesus and Mary (en adelante, ACSH), Marriage Register (from August 30, 1947).

167 Cfr. Memorandum de Gustav J. Schultheiss a John J. Maguire, New York, 23-III-1956, en AANY, CH-2-P, «Lobo, Rev. Leocadio». Schultheiss era Canciller de la archidiócesis de Nueva York y John J. Maguire el Obispo auxiliar.

Hispania Sacra, LXII

125, enero-junio 2010, 267-309, ISSN: 0018-215-X 
En 1956, el Carroll Club necesitaba realizar algunas obras que conllevaban, entre otras cosas, que el capellán perdiera su alojamiento. El vicario general de la diócesis, Edward Dargin, le propuso ser capellán de la parroquia de Sacred Hearts of Jesus and Mary. Lobo aceptó. Según Dargin, el sacerdote español era el candidato ideal. El párroco «instituted a Mass for the Puerto Ricans with Father Lobo as the Celebrant and he has been most successful. Father Lobo also hears confessions for the Puerto Ricans on Saturday evenings, has catechetical classes on Released Time for the Puerto Rican children and also has classes five evenings a week to teach English to the Puerto Rican people. (...) Father Lobo is loved by the people». ${ }^{168}$

Con sesenta y nueve años, regresaba al trabajo parroquial. Durante el siguiente trienio trabajó con intensidad, a pesar de que su salud comenzaba a resentirse. Los registros parroquiales son elocuentes: en el periodo 1956-1958 celebró anualmente 45 bautizos y 5 bodas, además de las misas y confesiones diarias. ${ }^{169}$

Leocadio enfermó de cáncer en 1958. Su salud se deterioró drásticamente, pero siguió atendiendo la parroquia en la medida de sus posibilidades. El 16 de mayo de 1959 ofició el último bautizo. Dos meses más tarde, el 11 de julio, Lobo falleció en el hospital St. Vincent. ${ }^{170}$ Después de celebrarse una misa de funeral en la parroquia de Sacred Hearts of Jesus and Mary, fue enterrado en el cementerio de St. John, en Brooklyn. ${ }^{171}$

\section{CONCLUSIONES}

Leocadio Lobo fue un sacerdote católico que encontró en el sacerdocio el sentido de su existencia. Su primera pasión fue la celebración diaria de la misa, a la que unía la administración de los demás sacramentos. Le movía el deseo de evangelizar, de servir a los hombres para acercarlos a Dios. A lo largo de su vida, Lobo tuvo una abnegada y constante dedicación a su ministerio.

Su visión de la sociedad estuvo marcada por su origen humilde, por la formación recibida en el Seminario, por su contacto parroquial con personas de to-

168 Edward V. Dargin a John J. Maguire, New York, 11-IV-1956, en AANY, CH-2-P, «Lobo, Rev. Leocadio».

169 Cfr. ACSH, Marriage Register (from August 30, 1947); Baptismal Register, no. 3 (from May 20, 1933 to June 25,1957$)$.

${ }^{170}$ La prensa americana reseñó esta defunción, subrayando la labor pastoral de Lobo como capellán en la iglesia de Sacred Hearts of Jesus and Mary, así como su apoyo a la España republicana durante la Guerra Civil: New York Times, 13-VII-1959; The Washington Post, 14-VII-1959.

171 Cfr. John J. Maguire a Leopoldo Eijo Garay, New York, 13-VII-1959, en AANY, CH-2-P, «Lobo, Rev. Leocadio». 
dos los estratos sociales, por su trato con los católicos republicanos y, más tarde, por su actuación política durante la Guerra Civil. Definía a la sociedad como un pueblo, y entendía que la misión del sacerdote era de liderazgo. El concepto «pueblo español» reunía para Lobo la quintaesencia del tradicionalismo cultural pasado por el cedazo de su republicanismo: una visión idealizada de los españoles que, libres de clases y ayudados por el clero, harían un cambio social acorde con el Evangelio. Rechazó las ideas político-culturales de aquellos católicos tradicionales que, encabezados por el primado, el Cardenal Gomá, deseaban que la sociedad no cambiase. Para Lobo, la sociedad de «orden» que pedían esos católicos no era otra cosa que una enésima propuesta de inmovilismo cultural, un anclaje en la tradición de la España confesional de siglos anteriores.

La Guerra Civil fue una tragedia para todos los españoles. Los católicos republicanos, al no encontrar acomodo con unos ni con otros, trabajaron con la esperanza de que fuera posible su sueño para España. En este tiempo, Lobo tomó partido y eso marcó su conducta. Calificó de «fascistas» o «enemigos» a los partidarios de los nacionales. Comparó el régimen de Franco con el de Hitler. Utilizó terminología marxista y dijo que era posible convertir a los comunistas, pero no afrontó con rigor intelectual su ideología atea. Responsabilizó de la Guerra Civil a la Iglesia española, en especial a los Obispos, porque había abandonado su deber evangelizador, pero olvidó lo hecho en este terreno en décadas anteriores. Absolvió políticamente la actuación del Gobierno republicano y no protestó por los asesinatos de clérigos en el segundo semestre de 1936. No censuró la falta de libertad política y ciudadana que oprimía a los católicos en la zona republicana y, en cambio, colaboró frecuentemente con la propaganda.

Leocadio Lobo obedeció a su Obispo, Leopoldo Eijo Garay y, más tarde, al Arzobispo de Nueva York, en todo lo relacionado con la disciplina de la Iglesia. Mantuvo una actitud sumisa en 1939 cuando se le comunicó que estaba suspendido a divinis: a pesar de encontrarse en una situación personal muy difícil, Lobo no contestó la sanción eclesiástica, sino que convivió con esa pena canónica, que tanto sufrimiento le causaba. Dio los pasos necesarios para ser rehabilitado y fue bien acogido por el Obispo de Madrid-Alcalá en 1947.

Lobo se enfrentó con la autoridad eclesiástica por razones político-culturales. Su pensamiento sobre el papel de la Iglesia y los sacerdotes en la sociedad fue opuesto al de la mayoría de los Obispos españoles, que apoyaron públicamente el régimen de Franco y unieron a éste la defensa de la religión católica. Por eso, el conflicto político más serio que mantuvo durante la Guerra Civil fue con el cardenal Isidro Gomá. Un segundo motivo de su crisis con la Jerarquía, como se vio al pedir la rehabilitación, fue la sustracción de documentos privados de su Obispo, que leyó y comentó ante terceros. 
Se manifestó pocas veces respecto a la persecución religiosa en la zona republicana, algo que llama la atención por la importancia de este hecho en la Guerra Civil, y porque muchos amigos suyos fueron asesinados. Cuando lo hizo, negó que la persecución hubiese sido de orden religioso. Para él, los católicos asesinados, clero y laicos, fueron castigados por sus ideas políticas. Concretamente, afirmó que los curas fueron masacrados por haber pertenecido o haber apoyado a los partidos y grupos de derecha.

Esta aseveración resulta insostenible, pues los asesinos manifestaron públicamente que deseaban borrar a la Iglesia de la sociedad para crear una nueva y, por tanto, no veían al clero como un problema solamente político, sino también social y cultural. Además, en ocasiones los asesinos fueron a por el sacerdote porque era «el cura», sin conocer ni preguntar su filiación política, cosa que estuvo a punto de ocurrirle al mismo Lobo al comenzar la Guerra Civil. Se persiguió al presbiterio con el fin de destruirlo sistemáticamente, y fue el grupo social con más muertes violentas: en Madrid capital fueron asesinados 704 de un total de 2.000 presbíteros.

Trató de condenar la violencia contra todos los inocentes, de uno y otro lado, pero, al aducir razones políticas por el asesinato del clero simplificó la realidad, omitiendo estudiar cada situación. Y aun en el caso de que hubiese estado acertado su análisis, la eliminación sistemática de sacerdotes por razones políticas era condenable sin paliativos.

Los últimos veinte años de Leocadio Lobo, vividos en Estados Unidos, estuvieron marcados por el reencuentro con el ministerio sacerdotal, la amistad con los republicanos en el exilio y la nostalgia. Lobo dejó de hacer declaraciones políticas en público. Desarrolló una labor parroquial semejante a la que había tenido en Madrid. Esta vez los necesitados eran los puertorriqueños de Nueva York: ellos fueron quienes más se beneficiaron de su entrega pastoral.

Este sacerdote, que amaba a España, a su esencia católica y a su futuro republicano, al acabar su existencia pudo acordarse unas palabras que había escrito en Las Migajas: «Recordemos, antes de poner punto final, las palabras del famoso protestante cuya madre inquiría en su lecho de muerte: "Hijo mío, dime: ¿cuál es la verdadera religión?". "Madre: para vivir puede valer cualquiera, quizá lo mejor sea no tener ninguna; pero para morir, ninguna vale si no es la Religión Católica"».172 Su funeral y su sepultura en el seno de esta Iglesia cierran una vida, en la parece cumplirse la plegaria de Rainer Maria Rilke: «El Señor da a cada uno su propia muerte; el morir que brota de su vida, para que tenga amor, sentido y urgencia... la gran muerte que cada uno lleva en sí es el fruto, en torno al cual gira todo». ${ }^{173}$

172 Leocadio Lobo CANÓNIGo, Las Migajas, 22-VIII-1929, p. 8.

173 Rainer María RILKE, «Señor, concede a cada cual...», en Obra Poética, Buenos Aires, Librería Perlado Editores 1956 (segunda edición), p. 132. 